Portland State University

PDXScholar

$7-29-2020$

\title{
The Experience of Female Caregivers in the Kingdom of Saudi Arabia
}

Nouf Albugami

Portland State University

Follow this and additional works at: https://pdxscholar.library.pdx.edu/open_access_etds

Part of the Sociology Commons

Let us know how access to this document benefits you.

Recommended Citation

Albugami, Nouf, "The Experience of Female Caregivers in the Kingdom of Saudi Arabia" (2020).

Dissertations and Theses. Paper 5504.

https://doi.org/10.15760/etd.7378

This Dissertation is brought to you for free and open access. It has been accepted for inclusion in Dissertations and Theses by an authorized administrator of PDXScholar. Please contact us if we can make this document more accessible: pdxscholar@pdx.edu. 
The Experience of Female Caregivers in the Kingdom of Saudi Arabia

by

Nouf Albugami

A dissertation submitted in partial fulfillment of the requirements for the degree of

Doctor of Philosophy

in

Sociology

Dissertation Committee:

Ginny Garcia-Alexander, Chair

Hyeyoung Woo

Emily Shafer

Kelly Gonzales

Portland State University

2020 


\begin{abstract}
In the Kingdom of Saudi Arabia ("KSA"), a minimal amount of research concerning the availability and level of social support specifically targeting the female caregiver has been conducted. Moreover, the extent to which social support has helped alleviate both the physical and psychological stress of caregiving has been studied very little, if at all. In light of this limited amount of research, the goals of this study are to investigate the following two questions: (1) What is the experience of female caregivers with chronically ill children in KSA, and (2) What is the nature and availability of social support among these women? To address these questions, this dissertation relies on semistructured interviews and surveys administered to 35 female caregivers of chronically ill children. The surveys incorporated questions dealing with the general experiences that each respondent was exposed to as a caregiver, the perceptions of their individual overall health, and other relevant demographic information. The interviews allowed for exploratory probing and explored women's perspectives on the quantity and quality of social support available to them, experiences with caregiving and caregiver burden, family structure and roles, and impacts to quality of life.
\end{abstract}

As a citizen of the KSA, I was able to obtain access to and recruit female caregivers within the clinical settings of King Fahd Medical Center, located in the city of Riyadh. With the oversight of a patient coordinator, I administered a caregiver survey and conducted face to face interviews with these women lasting approximately 2 hours per interview. The women who participated were ages 21 to 50. Most reported that as 
mothers, they were the primary caregivers. A majority of the participants had a high school education or less with a low rate of literacy, while the remaining participants' education ranged from a two- year degree to University studies or more. Most of the participants (71.4 percent) are married, and the majority of responded that they lived within a nuclear family structure and had from 1 to 4 children. Approximately a third of the respondents indicated that their overall health has deteriorated over the past year due to the stress of their caregiving duties. Moreover, a majority of the caregivers spend more than 16 hours caring for patients. The demands this level of care placed on the caregivers was evidenced by the sense of social isolation they experienced. Several key themes emerged with respect to women's perception of support and its role with respect to quality of life. Participants expressed intense pressures and demands related to the care of a chronically ill child, which commonly produced deleterious impacts on their physical and mental health. They expressed frustration over a lack of recognition of caregiving burden among medical professionals and family members alike. Women in the KSA reported very little formal social support, and there was little to no evidence of institutionalized support structures such as support groups or professional personnel who might offer resources for coping or other tools. However, they did report that they received informal emotional support from members of their immediate family including husbands and sisters. Analysis revealed that these female caregivers received support in the form of emotional, informational and instrumental support, all of which were 
accessed via the respondents' informal social support network of immediate family and friends, the latter of which was cultivated via social media.

This study yielded important insights into Saudi culture and how firmly it is structured along gender lines. Instances reflecting this were seen in responses from the participants where they perceived themselves as failing as wives because they were not able to meet other family members' needs or where they felt the need to demonstrate their ability to be emotionally strong by not soliciting sympathy from others. This study also provided insight into how during times of critical stress, like caring for a chronically ill child, chronic illness may provide an opportunity to abandon cultural norms as was evidenced by how close both spouses became during their child's illness. This seems to suggest that spousal/emotional support might be a very important component of a successful social support system in KSA and adds to our knowledge of the role of social support among female caregivers in the KSA. Implications for further research and the role of social support are discussed. 


\section{DEDICATION}

I dedicate this dissertation to my parents Mohammad and Fawzyah, as well as to my brothers and sisters back in Riyadh. I dedicate this dissertation to my family, who continues to be a powerful force in helping me to accomplish my lifelong dreams. This dissertation has not just been a compilation of knowledge acquired during the years at PSU, but an extension of my family. Not only have my parents and siblings played a fundamental role in my life, but also my elders who supported and raised me to be the woman I am today by instilling cultural values, enduring lessons, and prayers into my existence. What you have done for me can neither be measured with words, nor can it ever be repaid except by my efforts to excel using the knowledge that I have acquired. I love you all and I thank you for my life.

I also dedicate this dissertation to all of my friends here in Portland. Coming from such a long distance, you welcomed me with open arms and made me feel at home in a strange land. Thank you especially for your encouragement when the rain would come, constantly reminding me that July would indeed arrive and the sun would shine once again. I could not have asked for better friends. You mean the world to me. Thank you.

Finally, I owed my deepest thanks to my husband Khalid for his love and support over these past 5 years. You've been there when I needed you most and without you in my life I would be lost. And to my brother Khalid M. A sister could not have asked for a better brother to support her as she pursued her dream of earning a PhD. You as well have been there when I needed some reassurance that the impossible was possible. 
Thank you. And lastly, but not least, to my 5 wonderful children, Bader, Reema, Fahd, Lama and Mohamad for their patience and willingness to put up with the small sacrifices of their comfort in order to help me get through this work. You are my joy and for me you shine like the brightest stars in the night sky and are a constant reminder that goodness does exist in the world. I love you all from the bottom of my heart. 


\section{ACKNOWLEDGMENTS}

The undertaking and writing of a dissertation is not the outcome of the efforts of just one individual. Many people have contributed to its development and, ultimately, to its success. At this time, I take the opportunity to acknowledge those who have made an incredible impact on my doctoral journey and accomplishment. First and foremost in the name of Allah, the Most Gracious and the Most Merciful Alhamdulillah, all praises to Allah for the strengths and His blessing in completing this thesis. Special appreciation goes to my supervisor, Dr. Ginny Alexander-Garcia, for her supervision and constant support. Her invaluable help of constructive comments and suggestions throughout my research and thesis work has contributed immeasurably to its overall success. Her outstanding guidance and support over the last several years, from my first day in graduate school until this project became a reality, cannot be overstated. Without her support and valuable assistance, this project would never have come to fruition.

I also want to acknowledge my committee members, Dr. Hyeyoung Woo, Dr. Emily Shafer and Dr. Kelly Gonzales for their guidance and cooperation that enabled me to complete my research and graduate studies. Without their assistance, an already arduous task would have simply become overwhelming. Thank you.

I also want to express my deepest gratitude to the Portland State University Sociology Department, generally, and especially to the following professors whose impact upon me as a graduate student has been immense and for which words enough cannot communicate the depth of my respect for them as educators and for how they have 
taught me to think not only as an academic, but also as a human being. I have cherished your mentorship, and the knowledge you have imparted to me is invaluable: Melissa Thompson, José Padin, Julius McGee, Amy Lubitow, Maura Kelly and Dara Shifrer. My considerable thanks to each and every one of you

Also, I want to acknowledge and thank Bahar Jaberi and Kris Lucht-Adams for their kindness and considerable effort to always be available to assist me in overcoming any administrative difficulties I encountered, as well as finding the answer and solution that helped to bring this work to its completion. Thank you both.

Finally, I would like to thank and acknowledge Joy Mutare and Sara Golden. As my peers, your support during my journey sustained me during those times when I was at my wits end. You both served as my 24/7 hot line to answer my questions, provide me direction and suggestions to improve my work, explain ideas and concepts when I struggled with them, and provide me with the reassurance when I needed it most. I cannot thank you both enough for your friendship and for being there for me. 


\section{Table of Contents}

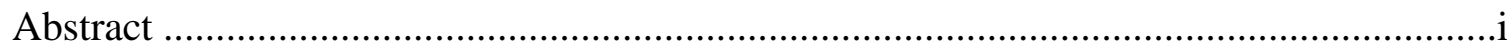

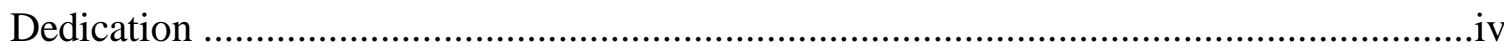

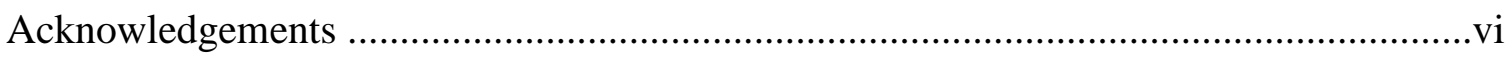

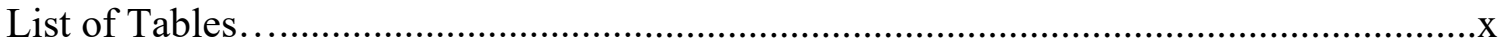

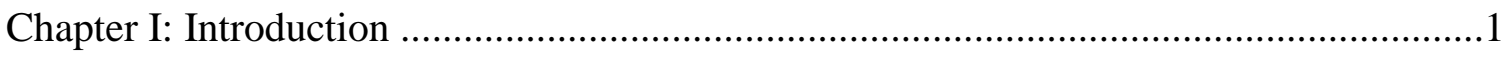

Chapter II: Literature Review ..........................................................................6

Theories Relevant to the Examination of the Importance of Social Support

Among Caregivers..........................................................6

The Buffering effect of Social Support.......................................... 11

The interplay of Quality of Life (Qol) and Social Support.......................... 13

Family Dynamics in the KSA............................................... 16

Women's Roles and Health in the KSA........................................22

Medical Setting in the KSA..............................................29

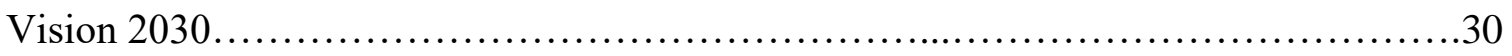

Health Services Personnel, Costs, and "Saudization" ................................. 32

Health Services Delivery and Approach in the KSA............................... 34

A frame of reference regarding the chronicity of illness............................. 37

Sickle Cell Disease - An overview........................................... 39

Social support and family functioning for children with Chronic Illnesses..............41

Chapter III: Research method and Data and Analysis ................................................44

Study Design............................................................44

Research Questions..........................................................45

Site Selection..........................................................46

Participants............................................................ 48

Data collection.............................................................49

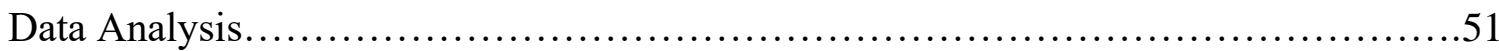

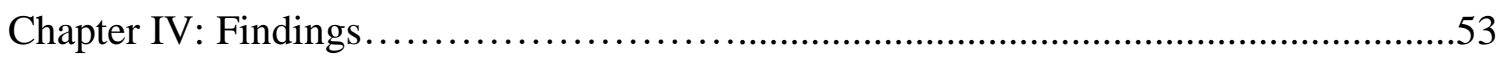

Quantitative Results ......................................................55

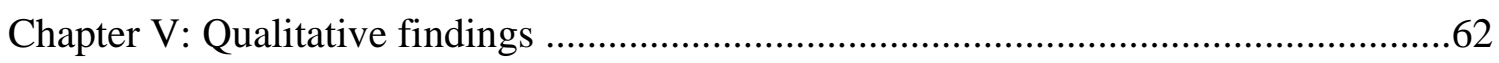

Theme 1: Caregiver's Quality of Life..........................................62

Caregiver's Health ............................................................65

Activity Limitation......................................................... 70

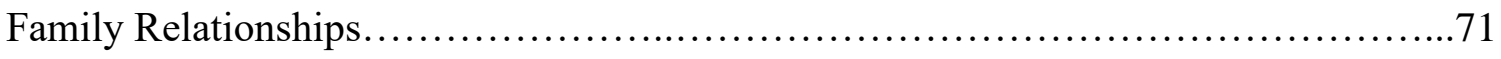

Social Life................................................................ 73 


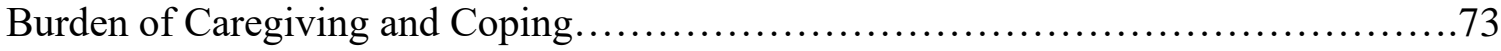

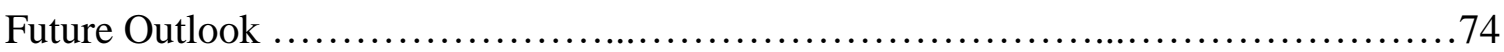

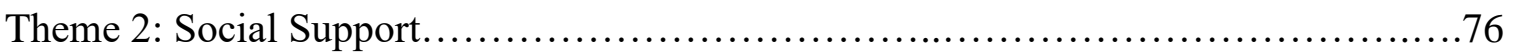

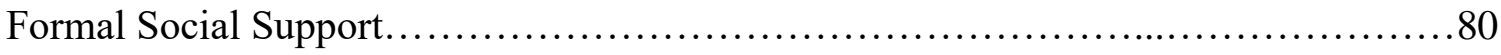

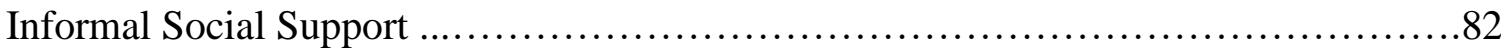

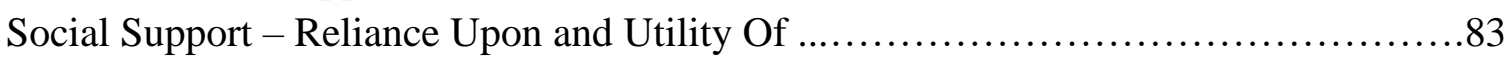

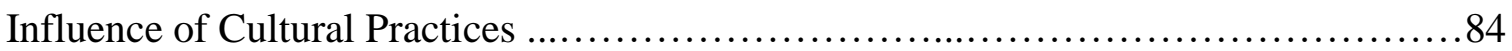

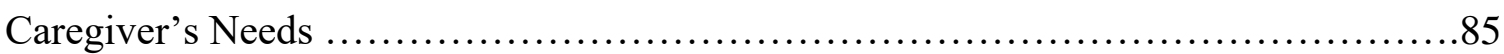

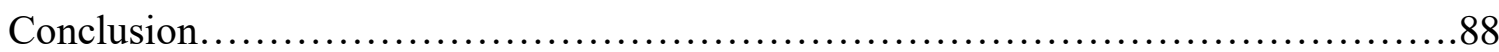

Chapter VI

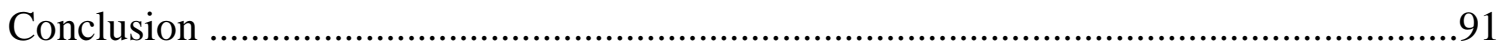

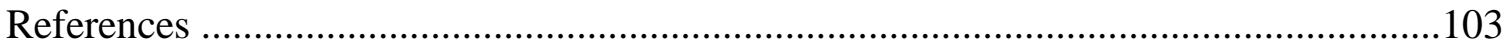

Appendix A

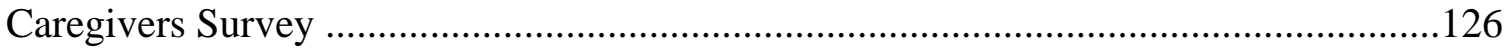

Appendix B

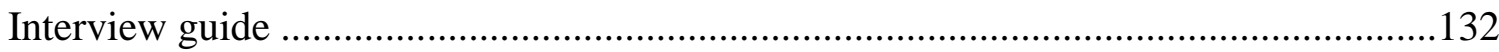

Appendix C

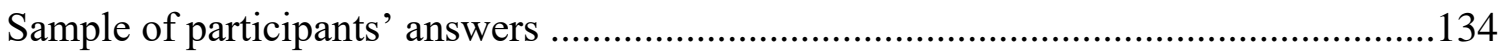

Appendix D

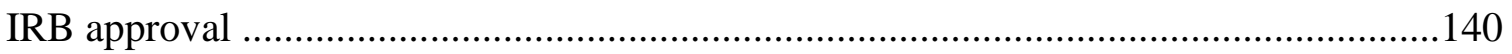

Appendix E

Approval by the head of children specialized hospital ...................................141 
List of Tables

Table 1

Participant Demographics...................................................56

Table 2

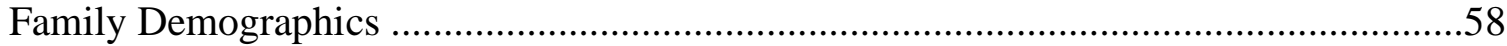

Table 3

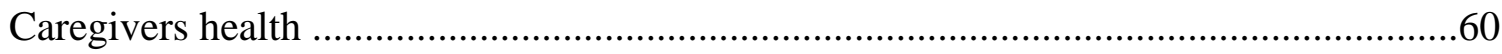




\section{CHAPTER I: INTRODUCTION}

The Kingdom of Saudi Arabia ("KSA") is a predominantly patriarchal society in which females are tasked with primary caregiving and the oversight of households. In instances in which there is a chronically ill child present, caregiving demands are increased as the treatment of chronic illnesses and conditions does not always occur within the clinical setting (Martin 2007), and the burden of rendering the care necessary for the ill patient is one that is shouldered most often by the mother or dominant matriarch of the family. Primary caregivers of chronically ill children may also experience additional psychological and physical strains. For example, caregivers of children with a chronic illness, in particular family members, are burdened with missed work, increased family stress, and increased demands due to the unpredictability of how the chronic illness manifests itself (Moskowitz et al., 2007).

In the KSA and other high-income Arab countries, disease patterns have changed such that infectious diseases have been replaced by chronic illnesses as the primary contributor to the overall disease burden (Mokdad et al. 2014). In fact, over the past twenty years, there has been an alarming increase in the prevalence of chronic diseases among children in Saudi Arabia, such as diabetes, hypertension and heart disease, cancer, genetic blood disorders and childhood obesity (Al-Qurashi, ElMouzan, Al-Herbish, AlSalloum \& Al-Omar, 2008; Al-Turki, 2000; World Health Organization (WHO), 2010). Given these increases, not only will the total number of caregivers who will be burdened with caring for chronically ill children increase, but so too will the dimensions of the burden that the caregivers have to bear. 
Much scientific evidence is available that has readily dissected the nature of chronic diseases and illnesses and the physical and psychological ramifications that they have upon the patient. But what has been overlooked by the medical establishment is the impact these diseases and illnesses have upon the caregiver; and in some milieus that impact is more significant than in others. This is especially true when certain cultural traditions and restrictions come into play. Particularly relevant to this point is the issue of how women in the KSA are challenged by the demands of providing care to a child or other family members afflicted with a chronic disease or illness.

It is well established that in the KSA, mothers are the ones charged with overseeing the welfare of children. In addition to the concerns noted above, those who are primary caregivers of one or more chronically ill children must also face the task of navigating the medical community to better understand the nature of the illness; often without the benefit of a suitably educated proxy to serve as an ombudsman with the hospital and doctors. Further complicating this issue is that, while Saudi women are primarily responsible for their children's health matters, they do not have legal authority to act as the primary decision-makers regarding health matters of family members.

Moreover, the demographics of the KSA point to a dramatic shift away from extended families, typically found in the rural areas, in favor of nuclear families which are predominantly found in the urban hubs of the KSA (Hamdan 1990). As changes to family structures and dynamics continue, it is possible that there will be an increased 
burden placed upon the female caregiver as a result of reduced proximity to her relatives available to assist with caregiving duties.

To date, little is known about the extent to which females in the KSA have access to or utilize social support. Importantly, researchers have found, both internationally as well as in the United States, that countries with stronger social support systems and adequate medical care facilities not only positively influence the chronic disease burden, but also "that higher levels of social support are associated with improved clinical outcomes [and] reduced psychosocial symptomatology.” (Midence \& Shand, 1992; Strom \& Egede, 2012; Shiba, Kondo \& Kondo 2016). Such systems are grounded in educational institutions, marriage and family settings, and availability of funds. It is unclear whether and how women access social support in the KSA. What is clear is that the Saudi society of today has not institutionalized the concept of "social support" as a mechanism to help families with a chronically ill child.

Accordingly, the focus of this dissertation is to more closely examine the burden of dealing with the administration of- and ongoing care for the chronically ill patient. Additionally, this study explores the extent and availability of social support as well as its perceived importance to those caregivers who are tasked with caring for a chronically ill patient. Two questions related to this investigation that serve as the main focus are as follows: (1) "What is the experience of female caregivers in the KSA who are caring for chronically ill patients?" (2) "What is the nature and availability of social support among these women?" 
To address these issues, this dissertation uses a combination of qualitative and quantitative data collected from thirty-five female caregivers of chronically ill children who completed a Caregiver Survey [see Appendix A] and semi-structured interviews [Interview Guide, Appendix B]. Surveys and interviews were conducted within the clinical settings of King Fahd Medical Center, located in the city of Riyadh. Because the spectrum of chronic diseases and illnesses is a broad one encompassing such conditions as coronary heart disease and cirrhosis to diabetes and depression, the universe of chronic conditions addressed in this dissertation was restricted to the most common chronic conditions that tend to strike children ranging in ages from birth to the mid-teens in the KSA. Data collected via surveys provide standardized responses on familial structures, caregiving experiences, self-rated health, and demographic data. Interviews were designed to provide in-depth exploration of perceptions and feelings about illness, women's perceived level of support and use of support services, and impacts on quality of life including relationships, employment, and health, among other concerns.

As will be described in the next chapter, the Kingdom of Saudi Arabia is in the process of undergoing profound changes. It has recently experienced a shift in disease patterns with chronic illnesses emerging as the primary contributor to morbidity and mortality; women's roles are changing in the face of increased education and economic opportunity; and, family structures are transitioning from traditional, extended forms to nuclear units. Exploration of the insights and experiences of female caregivers of chronically ill children in the KSA offers a unique opportunity to examine the impacts of 
these changing patterns on family dynamics as well as the health and well-being of the caregiver herself. In addition, it allows for an assessment of the presence and nature of social support in a context in which family structures and dynamics are potentially in flux and social support systems have not been institutionalized. Another compelling reason to undertake this research has to do with the fact that as the state-of-the-art medical treatments continue to evolve, children with chronic illnesses are potentially living longer. And, as these same children live beyond the expected lifespan of a chronic disease sufferer, the psychosocial impact of the disease on the patient and their families becomes a more significant issue. Accordingly, this dissertation attempts to shed light on these processes and add value to the existing field of Medical Sociology. 


\section{CHAPTER II: LITERATURE REVIEW/THEORY}

The focus of this literature review will be on the importance that social support plays as a vital mechanism in easing the significant burden shouldered by the caregivers of chronically ill patients. As such, it offers some detail on how social support is conceptualized and summarizes the literature on the beneficial role of social support on health and well-being. Additionally, this literature review considers (1) family dynamics and women's roles in the KSA (including what is known about the type and prevalence of social support afforded to family care givers); (2) the medical setting in the KSA; and (3) a brief summary of chronic disease prevalence.

\section{Theories Relevant to the Examination of the Importance of Social Support Among Caregivers}

When the term "social support" is used, it is usually referring to the functional content of social relationships, i.e. the help we receive from others. In this respect, "support" commonly indicates help, aid, assistance, nurturance, and comfort, for example, that can be directly or indirectly conveyed through actions, words, and deeds. Implied in the idea of support is that the actions, words, or deeds have an intended purpose or positive effect, typically to mitigate adversity or psychological discomfort. Indeed, however, this will not always be the case, since there will be instances where actions meant to be supportive will be counterproductive, while in other cases, actions occurring simply in the course of everyday interaction will have an unintended support quality. Social support implies that this help, assistance, or comfort is a product of, or is derived from, interpersonal relationships. In other words, social support is an 
interpersonal transaction involving the expression of comfort and positive affect, as well as the provision of help or aid, such as information and materials for example (Antonucci, 1985; Antonucci \& Israel, 1986; House, 1981; Kahn \& Antonucci, 1980). Additionally, this support is intended by the donor, or perceived by the recipient, to be beneficial to the recipient (Shinn, Lehmann, and Wong, 1984).

Implicit in this conceptualization is the view that social support can be viewed from two perspectives: (1) enacted support and (2) perceived social support. Enacted support refers to actual helping behaviors, such as actions, words, and deeds that others perform when they provide assistance to the recipient (Barrera, 1986). Enacted support is also referred to as "perceived support". Perceived social support refers to the "generalized appraisal that individuals develop ... that they are cared for and valued, that significant others are available to them in times of need, and that they are satisfied with the relationships they have". (Heller, Swindle, \& Duesenbury, 1986, p. 300).

Researchers have identified and examined three types of social support: emotional support, informational support, and instrumental support. Emotional support refers to demonstrations or assertions of love, caring, esteem, value, empathy, sympathy, and group-belonging (Thoits, 1985, p. 53). Emotional support, also referred to as esteem support and expressive support, is what most people mean when they speak of social support (Turner, 1983). Informational support includes the communication of opinion, facts, guidance, suggestions, and advice relevant to a person's current difficulties that might make an individual's life circumstances easier to manage (Thoits, 1985, p. 53). 
This type of support has also been called cognitive support or advice. Instrumental support refers to actions or the provision of materials that enable the fulfillment of ordinary responsibilities, such as household, childrearing, financial, and job-related obligations (Thoits, 1985, p. 53). Instrumental support has also been called practical support, tangible support, or material support.

As a concept, the term "social support" has been a part of sociological parlance beginning as early as 1970 when three medical practitioners John Cassel, Sidney Cobb, and Gerald Caplan began independent investigations into its impact in the area of health. The team of Cassel and Cobb were among the first investigators to examine the evidence of just how effective and therapeutic the impact of social support could be in terms of promoting health maintenance. Within the literature dealing with social support, there is a growing body of research suggesting that social support may "buffer or allay the harmful effects of stressful life events on psychological and physical health" (Cassel, 1976; Cobb, 1976; Henderson, Byrne, Duncan-Jones, et al, 1980; Kaplan, Cassel, \& Gore, 1977). According to the buffering hypothesis, social support modifies or mitigates physical and mental health problems, but only in the presence of high stress conditions or adversity (Cobb, 1976; Cohen \& Wills, 1985; Lin et al., 1985). Cassel (1976) independently separated the various social conditions in terms of their functionality in providing both protective influences on health as well as their capacity to produce illness. To this end, Cassel addresses the term social support in terms of its ability to provide "protective factors buffering or cushioning the individual from the physiologic or psychological 
consequences of exposure to the stressor situation" (1976: 113). Cobb (1974, 1976), on the other hand, viewed social support from what can best be called a communication perspective. According to Cobb, "social support is conceived to be information belonging to one or more of the following three classes: (1) Information leading the subject to believe that he is cared for and loved; (2) Information leading the subject to believe that he is esteemed and valued; [and] (3) Information leading the subject to believe that he belongs to a network of communication and mutual obligation" (1976: 300). Cobb argues that "supportive interactions [i.e. social support] among people are protective against the health consequences of life stress" (1976:300). On the other hand, Caplan (1974) considers the idea of a support system as "an enduring pattern of continuous or intermittent ties that play a significant part in maintaining the psychological and physical integrity of the individual over time", and enumerates three types of support activities: "The significant others help the individual mobilize his psychological resources and master his emotional burdens; they share his tasks; and they provide him with extra supplies of money, materials, tools, skills, and cognitive guidance to improve his handling of his situation." (1974: 6-7). Dean and Lin (1977) view social support as a function fulfilled by the "primary group" which is best exemplified by the family. In this role as the primary group, the family has the following distinct features: “a) emphasis on mutual responsibility, caring and concern; b) strong mutual identification; c) emphasis upon the person as a unique individual rather than upon his/her performance; d) face-to-face interaction and communication; e) intimacy; f) close 
association and bonds; and g) provision of support, affection, security, and response" (1977: 407).

Berkman (1984) sees social support as "the emotional, instrumental, and financial aid that is obtained from one's social network" (1984: 415). Berkman adds that support "is generally considered as an exchange or transaction between people" (1984: 415) which seems to dovetail with the assessment by House (1981) who "suggests that support involves a transaction of (a) emotional concern, (b) instrumental aid (goods and services), (c) information, or (d) appraisal (information relevant to self-evaluation)" (1984: 415). Berkman is careful to draw a distinction between social support and its relationship to social networks stating that the latter may or may not be therapeutic to the recipient while the intent of the former is to ameliorate an already stressful situation. Regardless, it is important to address the concept of social networks to distinguish it from social support, which is the focus of this paper. A social network is "a specific set of linkages among a defined set of persons, with the additional property that the characteristics of these linkages as a whole may be used to interpret the social behavior of the persons involved" (Mitchell 1969:2). In effect, social support is a product of social networks. Berkman (2012) expands on Mitchell stating,

"Social networks are comprised of multiple ties with family, friends, and links to more formal and informal social institutions. These ties form a web that provides resources to its members, often in the form of social support. Social support itself takes a number of forms, including emotional, instrumental, appraisal, and 
financial support. Social ties need not be positive but can also lead to negative outcomes including conflict and abuse" (2012: 263).

For discussion purposes, and to more closely comport to the meaning intended in this study, social support is defined based on the Berkman (1984) and House (1981) definitions of social support resulting in a composite definition that sees social support as "the aid - the supply of tangible or intangible resources - individuals gain from their network members" (Song and Son, 2011: 6).

The Buffering effect of Social Support

The physical and mental health effects of stress will be most pronounced for those individuals with little or no support. When support levels are low, the relationship between life stress and sickness should be strongly positive during periods of high life stress. Conversely, when support levels are high, the relationship between life stress and illness should decrease under similar circumstances (Wilcox, 1981). At relatively low levels of stress, social support is irrelevant to the situation because there is little or nothing to buffer (Gore, 1985; Lin et al., 1985). In statistical terms, the buffering model specifies that an interaction exists between the stress variable and the moderator variable, in this case, social support (Aneshensel \& Stone, 1982; Kaufmann \& Beehr, 1989).

A number of studies have demonstrated that there are significant associations between greater support and reduced caregiver burden (Bull, 1990; Caserta, Lund, Wright, \& Radburn, 1987; George, 1987; George \& Gwyther, 1986; Given, Stommel, Collins, King, \& Given, 1990; Miller \& McFall, 1991; Montgomery, et al., 1985; Pratt, 
Schmall, Wright, \& Cleland, 1985; Robinson, 1990; Scott, Roberto, \& Hutton, 1986;

Zarit, Reever, \& Bach-Peterson, 1980). Moreover, previous research has shown a consistent inverse relationship between the quality of social support and caregiver burden. (Del-Pino-Casado, R., Frías-Osuna, A., Palomino-Moral, P. A., Ruzafa-Martínez, M., \& Ramos-Morcillo, A. J., 2018; Vrabec, 1997). Additionally, several studies indicate that the effect of stress on symptomatology, i.e. conditions of physical or mental distress such as depression, heightened fatigue, loss of appetite, differs at varying levels of social support (Aneshensel \& Stone, 1982; Baron \& Kenney, 1986; Kaufmann \& Beehr, 1989; Lin et al., 1985).

Caregiving, especially when that caregiving requires an extensive time commitment, tends to have a deleterious impact on the caregiver, both mentally and physically. Prior work has measured the physical impacts with Allostatic Load (AL), and findings suggest that the absence of social support plays a pivotal role. For example, the research team of Brooks, Gruenwald, Karlamanga, Hu, Koretz and Seeman (2014) concluded that "higher levels of spouse negativity, family negativity, friend contact, and network level contact were each associated with higher AL, and [that] higher levels of spouse support were associated with lower AL" (2014). Moreover, it is not just the quality of the social support, but the quantity of social support as well. When this social support is either non-existent or at a bare minimum, the impact upon the caregiver is not favorable. With this as background, the theory chosen to help explain the importance of the role of social support among female caregivers is the buffering hypothesis theory. 
The reason for this is that based on this theory, it will underscore that during instances of significant stress among caregivers engaging in caring for a chronically ill child, both the amount and quality of social support will act to buffer the manifestations of both physical and psychological impact on the caregivers thereby making the burden of their care more bearable.

The interplay of Quality of Life (Qol) and Social Support

An important component of the proposed study is quality of life (QoL). As

described below, this may be conceptualized in a number of ways; however, the primary components of physical functioning, mental status and ability to engage in normative social interactions are generally agreed upon indicators. Accordingly, similar measures are incorporated to assess quality of life among caregivers in KSA. According to Canam \& Acorn, "assessment of quality of life (QoL) is still developing as an area of clinical research, with researchers continuing to refine the concept." (1999: 192). One review found a variety of terms equated with QoL: life satisfaction, self-esteem, well-being, health, happiness, adjustment, value of life, meaning of life, and functional status (FrankStromborg 1988). Another review of the literature identified the main attributes of QoL as: (a) psychological well-being (satisfaction with life, meaning of life, goal achievement, and happiness); (b) physical well-being (activities of daily living, appetite, and sleep); (c) social and interpersonal well-being; and (d) financial and material well-being (Padilla, Grant, and Ferrell 1992). Others identified the central domains of QoL to be life satisfaction, self-esteem, health and functioning, and socioeconomic status, and consider 
life satisfaction to be the crucial indicator of subjective QoL (George \& Bearon, 1980). The foregoing suggests that there is no consensus as to what is or should be the proper definition of QoL (Spitzer 1986). However, most researchers utilize measures that incorporate three dimensions including physical function, mental status, and engagement in normative social interactions (Post 2014), and this dissertation conforms to those standards by applying questions taken from the domains identified by Frank-Stromborg (1988), Padilla, Grant, and Ferrell (1992), and George and Bearon (1980).

It is well-accepted that caregiving for a chronically ill family member may potentially lead to consequences for such caregivers in terms of quality of life (Baanders \& Heijmans 2007). Furthermore, researchers have demonstrated that chronic illness leads to stress, which affects normal family functioning and structure (Bain, 1998; Barlow \& Ellard, 2006; Bellin \& Kovacks, 2006). Given prior research documenting the importance of social support in improving health and well-being (Amendola et al, 2010; Reblin \& Uchino, 2008; Jensen et al. 2014; Thoits 2011; Umberson and Montez 2010), it is reasonable to surmise that the caregiver's burden may lessen due to the involvement of others. As Goldberg (2011) states, "We have seen how the involvement of families and caregivers improves the quality of life for the patient, eases caregivers' burden, encourages adherence to treatments and increases patients' ability to cope with the illness.” (2011: 41). Another study reports, "caregivers with partners had higher mean scores in the overall global assessment for QoL and health than those without partners. The results provide evidence of the influence of social support regarding Quality of Life 
and the burden perceived by family caregivers" (Amendola et al. 2010: 881). Similarly, Burnette et al. (2016) observed that women reported higher levels of psychological distress and reduced QoL than men, but that perceived social support mediated these impacts. In a study of children with Autism Specturm Disorder, McIntyre and Brown (2018) determined that "positive coping strategies in families of children with ASD are often associated with the presence of adequate social support" (95). Their work confirmed earlier findings indicating that higher levels of social support improved family adjustment (Henderson and Vandanberg 1992) and were associated with increased hardiness and physical and emotional wellbeing (Trivette \& Dunst 1992; Weiss (2002) in families raising children with ASD. The implication here is that not only does social support alleviate the physical and mental stress of the caregiver, but it also enhances their emotional well-being when they are allowed more time to focus on the important social relationships within the family, most especially with their spouse.

Though not limited to the context of caregiving and chronic illness, other studies have further confirmed the importance of social support for family functioning and structure. For example, natural disasters can mimic the same stress as that seen when a family has a member suffering from a chronic illness. As important as social support is to the family burdened with caring for a chronically ill family member, social support is equally as important to survivors of natural disasters. This is evidenced in the research of Ke et al. (2010) who demonstrated that social support is associated with improved quality of life in the survivors of an earthquake. Similarly, Hossein (2013), in his study of 
visually impaired subjects, found that blind students who enjoyed a high degree of social support also enjoyed a high degree of life satisfaction or QoL.

On the other hand, when a caregiver's situation is devoid of social support this may translate into measurable negative impacts to quality of life. In fact, some have observed reduced marital quality, i.e. emotional affection and love, in those caring for children with diseases (Al-Akour and Khader 2008). Researchers underscore this point in a study of Jordanian children suffering from asthma, a chronic health condition which has been shown to negatively influence QoL in affected children and parents. Their study observed a difference in emotional function and an association between the child's asthma and the family relationship (Al-Akour and Khader 2008). Though the asthmatic

condition was not the sole cause determinant of reduced QoL, it acted in concert with the lack of social support to exacerbate an already stressful situation. Similar studies have reported results that parallel this outcome. For example, a study of Albanian caregivers reported high levels of distress, poor QoL, and moderate levels of social support. (Burnette, Duci \& Dhembo, 2017).

\section{Family Dynamics in the KSA}

In less than a century, the KSA has evolved from a collection of tribes into the Arab world's most powerful nation state (Obaid, 2015). During this period, the traditional family structure of the extended family began to decline and the nuclear family has increased in prevalence. Many Saudi researchers have attributed these changes to Saudi family dynamics and structure to the discovery of oil in the KSA. 
Indeed, the discovery of oil in the KSA brought forth a multitude of changes that have affected virtually every aspect of Saudi life. The rapid development of technology has also brought about significant changes in Saudi society, not unlike those that occurred during the First Industrial Revolution, which transformed largely agrarian societies profoundly toward more modern and urban forms.

The KSA's oil reserves are among the largest in the world, and the wealth generated via global exportation has given rise to a cash economy and increased urbanization. This new found wealth has also given rise to modernization throughout the country as modern cities are supplanting rural villages. For example, tribal peoples, especially the Bedouins ${ }^{1}$, are increasingly leaving rural areas of the country to seek better economic opportunities (largely in the tourism and petroleum industries, the military and as self-employed shopkeepers where they sell handmade rugs and other Arabic goods) in urban areas (Browning, 2013). In fact, as of 201883.84 percent of KSA citizens now reside in urban areas (UN Population Studies, 2018: pg.2). Overall, these shifts have led to subsequent improvements in living conditions, better medical care, the utilization and application of technology, which has enhanced both the KSA's communications and transportation systems, and increased incomes among Saudi citizens.

\footnotetext{
${ }^{1}$ The Arabic term for "desert-dweller". The Bedouin are pastoralists specialized in camel breeding. Unlike pastoralists who specialize in the breeding and raising of other domesticated animals, such as cattle, sheep and goats, the Bedouin are almost self-sufficient. Nevertheless they are, to some extent, dependent on the settled lands. The Bedouin do not adhere to the practice of Islam with the same fervor as urbanized and settled Arabs. This group constituted the majority of the population in the KSA during the first half of the 20th century, but this number has steadily dwindled to $27 \%$ in 1974 and to less than $10 \%$ in the 1991(1411 H) census. (The Saudi Network 2008; Pietruschka 2006)
} 
These societal changes have also resulted in significant changes to family structures and traditions (Al-Khateeb 2008). As Hamdan (1985, 1990) points out, "marriage arrangements have changed [such that] people get married at an older age (20 years or more) and the person now assumes responsibility for choosing his wife" (1990, pg. 20). Moreover, "the marriage of cousins has decreased" (1990:154). Traditionally, an extended family model, consisting of two or three generations living in the same household, was the prevalent one in the KSA (Hamdan 1990: 90). In addition, marriages were, in the past, arranged such that the parents were the ones who selected appropriate marriage partners for both the bride and groom to be (Hamdan 1990: 154).

Since the KSA became a major exporter of oil, which began in the 1970s, the extended-family model has started to gradually disappear in Gulf societies in favor of nuclear families consisting of two parents and their children (Al-Ghanim 2013). For example, Saudi Arabia's largest city, Riyadh, has experienced rapid urban growth and a noticeable increase in the number of families living there, which are primarily composed of nuclear family units ${ }^{2}$ (worldpopulationreview.com/world-cities/riyadh-population). Moreover, during this same period there has been a concomitant decline in the extended family, made up of two spouses and their relatives. The period from 1996 to 2004 reflected this situation, as the nuclear family became the prevailing model, accounting for $67 \%$ of all families in 1996 and rising to $75 \%$ in 2004. The percentage of extended

\footnotetext{
2 "Currently, 75\% of the homes in Riyadh are considered nuclear. The previous census of 1996 indicated that only $67 \%$ of the households were considered nuclear." (http://worldpopulationreview.com/worldcities/riyadh-population/, 2020)
} 
families fell from $33 \%$ to $21 \%$ during the same period (SAHC 2004). Such shifts have been attributed to extensive urban migration and access to wealth as an increasing number of young couples have left their hometowns in favor of setting up their own single-family homes.

Another factor that has contributed to changing family structures is greater opportunities for Saudi women in the area of education. Indeed, access to greater educational opportunities for women has accompanied the rise of the nuclear family household. In 1980, a study conducted in Ad Dammam regarding the living arrangements of salaried Saudi women showed that of a sample of 100 salaried women, 91 percent had either a high-school or university education, and that more than 90 percent lived in a nuclear family household (Metz 1992). By contrast, in the same study, a similar sample size of rural women found that of the 91 percent of who were illiterate, only half lived in a nuclear family unit. Moreover, this same study revealed that the more educated, salaried women had an average of two children, while the illiterate and uneducated rural women had an average of 4.6 children. This is consistent with transitions from high to low fertility that have been observed across the globe, which have linked increased education among women to fewer children (via the postponement of marriage and childbearing). Accordingly, as the level of education rose so, too, did the age of first marriages. Again from the Ad Dammam study, "79 percent of the salaried women were over the age of sixteen (and most over the age of nineteen) when first married, whereas 75 percent of rural women were married between the ages of ten and twelve" (Metz 1992). Finally, 
and to underscore all of the above, Long (2003: 28) has stressed that "the rapid urbanization of the Kingdom is one of the reasons behind the gradual loss of traditional cultural values, and the transformation of the extended family into a nuclear family."

The prosperity experienced by the KSA since the discovery oil has had a beneficial impact on the overall role of Saudi women, both in the areas of education and in the labor force. During the period 2003 to 2013 when the price of oil worldwide skyrocketed to $\$ 110$ per barrel, the fortunes of the KSA were greatly enhanced. With this increase in revenue, "the government used oil revenue to invest in a range of developmental priorities. Public spending quadrupled during the decade, and about $\$ 450$ billion of public capital investment was deployed in programs to improve education, health, social welfare, infrastructure, and transport” (MGI, 2015, pg. 8). As an example, “in 1960, the budget for women’s education was two million Riyals (\$533,000 US), while in 1987, it was 4.8 billion Riyals (\$1.28 billion US)” (Hamdan, 1990, pg. 32). Technological advancements in education have led to increased female participation in the labor force. According to Hamdan, "one of the important technological devices [in educating Saudi women] can be seen in the women's division in the local universities. The faculty who teach women must be females, but at the university level of education, where this sometimes isn't possible, women are taught through the medium of live closed-circuit television, if the instructor is a male" (1990, pg. 54). By having greater access to higher education, Saudi women are beginning to see greater representation in the labor force. 
Heretofore, the only role of Saudi women was that of being a housewife, irrespective of whether she had children. However, with the push to modernize the KSA, and significantly increased access to higher education for women, Saudi women have been able to become more fully integrated in the Saudi labor force. As one scholar states, "one can observe women in many social and scientific jobs which were formerly considered the exclusive preserve of men" (Hamdan, 1990: pg.54). More importantly, education has allowed for Saudi women to become a social force with the KSA. Bahry (1982) eloquently and forcefully states the new position Saudi women find themselves: The emergence of Saudi women as a social force is one of the most dynamic of many changes shaping Saudi Arabia today. Today, Saudi women are clearly on the move, asking for and taking an increased role in the social and economic life of their country. There are now Saudi women doctors, university professors, mathematicians, scientists, social workers, bank directors, journalists, college deans and radio announcers, to mention just a few of the new occupations into which they have moved. And the ranks of these working women are constantly being replenished from a growing pool of educated women. (p. 502)

However, it is important to note that despite evidence of changes to family size and structure, increased levels of education and access to the labor force, and an expansion of roles and expectations beyond the domestic sphere, there still persists the immutable reality that these changes are occurring at a glacial pace and there remains much room for improvement. 
Women's Roles and Health in the KSA

The KSA is a country steeped in traditions, and there still predominates a social structure that dictates the roles of women and what their ultimate responsibilities are, as caregivers and overall. Indeed, religious norms permeate all Saudi life and culture. Such norms include male guardianship, described below, and the tradition of gender segregation in mosques, whereby the sexes are separated during times of worship. Similarly, in the classroom female students are educated separately from their male counterparts.

Contrary to popular misconceptions, with Islam women gained more rights. Accordingly, they are not restricted from attending college, working outside of the home, or even owning their own businesses, though women in traditional Saudi families are not expected to work outside the house (Sullivan, 2012). When a Saudi woman desires to work, whatever work she does cannot contradict her duties at home with her husband and children. Simply put, if a Saudi woman's work means that she will be neglecting her family, then she must defer to her duty as wife and mother and remain at home to take care of the family. Formally, Saudi families tend to be patriarchal, with the male being the head of the household (Al-Saleh, 2012).

In addition to their household duties, Saudi women are viewed as the primary caregivers in the family (Brown, 2005), and this extends to the care of sick children (Baghdadi, 2011; Elamin \& Omair, 2010; Flynn, 2011; Johansson, Anderzen-Carlsson, Ahlin \& Andershed, 2012). In the face of increased chronic illnesses, which are now the 
most commonly diagnosed form of illness in Saudi children (Al-Qurashi et al., 2009; Ng, Zaghloul, Ali, Harrison \& Popkin, 2011), women may encounter additional challenges as these forms of illness have been observed to generate physical and mental health strain on caregivers in other countries. Yet, women's roles in the KSA may influence or constrain their ability to ask for or receive assistance in the context of illness. One study of mothers of chronically ill children observed that, "Arab women have learned to hide their feelings and pretend that they are healthy, especially when they have any disease that might affect their social life" (Katooa et al. 2015: 69). Other studies have pointed to expectations that mothers should be strong for their families, as a rationale for these commonly held conceptions among women in the KSA (Cohen, Azaiza and Manassa 2013; Azaiza and Cohen 2008). Accordingly, any weakness, perceived or actual, must be hidden for the sake of the family. Additionally, women in the KSA must learn to cope with their problems and put up a strong front by being at the service of their family (Ali et al., 2008; Baghdadi, 2011; Elamin \& Omair, 2010; Memish et al., 2013).

Religious beliefs arguably play a role in the marginalized healthcare of Saudi women, and they may internalize religious beliefs such that they play a pivotal role in the healthcare they receive, and how quickly they receive this medical assistance. In fact, Saudi women have been found to delay the receipt of needed medical attention for myocardial infarction, or heart attack, and have attributed these delays to the need for a male relative's permission to seek care, an inability to travel unaccompanied, and beliefs that women shouldn't attract attention, among others (Aldosari 2017). 
In her study of gender norms and women's health Aldosari (2017) argues that gender norms pervade all aspects of life and are hugely influential with respect to women's health. She further observes that Saudi women experience differential treatment on the basis of cultural or religious justifications. She describes impacts on how healthcare is accessed by Saudi women in the following,

"Saudi Arabia has a unique culture in which gender roles and expectations are based on a specific interpretation of Islamic sharia. These roles are strictly enforced through legal and societal measures. Consequently, women may find health services inaccessible, unavailable, or conditioned on certain cultural justifications or gender norms. Limitations on women's autonomy, such as those imposed by the male guardianship system, women's driving ban, gender segregation, and religious norms, influence access, quality, and outcomes of health care for women in Saudi Arabia" (2017: 6).

Despite efforts to advance the opportunities of Saudi women in the areas of education and the labor force, their overall quality and standard of health is below that of Saudi men. As is described in a later section, "Health care coverage is universal and free for all [Saudi] citizens and legal residents according to Articles 31 and 32 of the Basic Law of Governance" (Aldosari 2017: 4). This mandate does not mean that Saudi women and men have access to the same quality of healthcare, however. The reality in the KSA is that the health care system is one that is gendered to the detriment of women. 
The gendered nature of the KSA's healthcare system that effectively marginalizes the physiological well-being of Saudi women masks an even more pernicious aspect regarding the health of Saudi women, namely the role of the guardianship system and the prevalence of violence against Saudi women. In fact, a recent report observed that $11.3 \%$ of women aged 15 and older experienced intimate partner violence in Saudi Arabia compared; comparatively $2.6 \%$ were reported in the United States (IHME 2017). A complete and detailed examination of this particular sociological issue is beyond the scope of this paper and actually warrants an exhaustive exploration on its own. However, the nature of the problem with the guardianship system and the violence perpetrated upon Saudi women can be succinctly summed up in an observation from Aldosari's study. She states,

"One of the most serious consequences of the vast authority granted to male guardians over women is violence against women and girls. The problem represents a major public health concern, with a wide array of adverse physical and mental health outcomes.

Gender norms such as male control of wealth and decision making in the family, isolation of women and family, control of a woman's mobility, and acceptance of the use of violence to resolve conflicts are strongly associated with the risk that such violence will occur." (2017, p. 7)

Finally, and especially apropos to the topic of this dissertation, is the association between caregiving and poorer health in Saudi women. These roles, along with reduced socioeconomic status, have been directly linked to stress and poorer health (Aldosari 
2017). Indeed, Aldosari's study (2017) observed widespread prevalence of metabolic syndrome, a collection of risk factors for cardiovascular disease, in Saudi women.

Scant attention to the role of social support among female caregivers in the KSA may be found. One exception is the work conducted by Katooa et al. (2015), which did observe a positive association between the presence of social support and ability to cope with stress. However, several participants reported that they did not receive any degree of social support at all. As mentioned previously, the authors suggested that expectations surrounding the roles of women and a desire to hide weakness may explain this. Another reason for limited attention to this concept may be attributable to the misconception that in the KSA, a tribal society at heart, the presence of extended family in daily life implies a degree of social support. In other words, Saudi researchers have presumed that female caregivers receive social support from their relatives. However, as the nuclear family has become the predominant social unit in the KSA (Todd et al 1977; Hamdan 1990; Al Sharfi 2017; Alkohaiz 2018), the availability of social support afforded by extended families is likely dwindling, which may lead to an exacerbated caregiving burden. Previously, the traditional extended family represented a ready resource for support and assistance. But now, given the demographic shift in favor of nuclear family units, siblings of parents or other close relatives are less available or accessible.

In Saudi Arabia, little attention has been devoted to the wellbeing of informal caregivers and the role of social support; hence, scarce coverage of this topic is apparent in the existing literature. As mentioned above, the only job that Saudi women had in the 
past was that of housewife or mother, assuming children are present. As Saudi women have increasingly gained access to education and become working professionals in their own right, their roles as mothers and primary caregivers have not shifted. Additional societal changes involving a shift away from traditional, extended family structures toward nuclear family units, along with an increased chronic illness burden, may lead Saudi women to experience deleterious physical and mental health in addition to increased role strain related to changing gender norms. Furthermore, an entrenched patriarchal structure suggests that the male in the relationship is not expected to assist with caregiving. Accordingly, studies that assess the degree of excess burden and associated ill effects experienced by Saudi women as well as the availability of social support are sorely needed.

Following from the immense wealth that seemed to appear overnight for the KSA and its citizens, the country also saw rapid changes in its urbanization, education and the overall push toward greater modernization, all of which were having profound effects on both Saudi society and Saudi families. More specifically, the extensive urban migration and access to wealth were breaking up the extended family household. This has been evidenced by the number of young couples who have left their hometowns in favor of setting up their own single-family homes. With greater urbanization and modernization came also greater opportunities for Saudi woman in the area of education. Consequently, the access to greater educational opportunities for women also encourages the rise of the nuclear family household. 
Notwithstanding this contemporary change in Saudi society that seems to favor women, there still predominates a social structure that dictates the role of women and what their ultimate responsibilities are, not just in terms of their roles as caregivers, but also in terms of what is expected of them overall. Contrary to popular misconceptions, with Islam women gained more rights. Though they are not restricted from attending college, working outside of the home or even owning their own businesses, women in a traditional Saudi family are not expected to work outside the house (Sullivan, 2012). But when a Saudi woman desires to work, whatever work she does cannot contradict her duties at home and with her husband and children. Simply put, if a Saudi woman's work means that she will be neglecting her family, then she must defer to her duty as wife and mother and remain at home to take care of the family. Saudi families tend to be patriarchal, with the male being the head of the household (Al-Saleh, 2012). Moreover, throughout history in the KSA, women took the role of caregiver for ill family members (Johansson, Anderzen-Carlsson, Ahlin\&Andershed, 2012). In addition to their household duties, Saudi women are viewed as the primary caregivers in the family (Brown, 2005). How this relates to the degree of Social Support within the KSA can be more properly understood with reference to the study conducted by Katooa et al (2015). The Katooa study highlighted the fact that in the KSA, "chronic illness is the most diagnosed type of illness among Saudi children annually (Al-Qurashi et al., 2009; Ng, Zaghloul, Ali, Harrison \& Popkin, 2011). Their study also evidenced that "the majority of the mothers participating in this study had the responsibility of caring for their children, because of 
the nature of the female role in Saudi Arabia (Ali, Mahmood, Moel, Hudson\& Leathers, 2008; Baghdadi, 2011; Elamin \& Omair, 2010; Memish, Zumla, Al-Hakeem, Al-Rabeeah \& Stephens, 2013). Moreover, "women are generally viewed as the primary caregivers for their sick children (Baghdadi, 2011; Elamin \& Omair, 2010; Flynn, 2011). While this study found that low level of support affected the caregiver's ability to cope with the stress involved, there were some respondents in their study who reported receiving no form of social support at all. Katooa et al further point out that "Arab women have learned to hide their feelings and pretend that they are healthy, especially when they have any disease that might affect their social life.”(pg. 69) Studies conducted by Goldblatt, Cohen, Azaiza and Manassa (2013) as well as Azaiza and Cohen (2008), have demonstrated that the way women in the KSA think is common because women who are also mothers are expected to be strong for their families. Moreover, the women in Saudi society are charged with the role of primary caregiver (Ali et al., 2008; Baghdadi, 2011; Elamin \& Omair, 2010; Memish et al., 2013). In this regard, any weakness, perceived or actual, must be hidden for the sake of the family. Additionally, women in the KSA must learn to cope with their problems and put up a strong front by being at the service of their family (Ali et al., 2008; Baghdadi, 2011; Elamin \& Omair, 2010; Memish et al., 2013).

\section{Medical Setting in the KSA:}

Though the KSA ranks among the top 20 richest countries in the world, its healthcare delivery system only ranks $26^{\text {th }}$ among all countries worldwide (Al-Hanawi MK, Khan SA, Al-Borie HM 2019). Formally, the governing body of the KSA has 
designated that health care is a fundamental right of all Saudi citizens. As such, a majority of the expenditures for healthcare have been funded by the Saudi government with public monies, with the Ministry of Health $(\mathrm{MOH})$ being the bureaucratic arm overseeing the delivery of these services (Al-Hanawi MK, Alsharqi O, Almazrou S, Vaidya K. 2018). Underscoring the KSA's deep commitment to improving the quality of health services to its citizens, the KSA apportioned a fund totaling over $\$ 39$ billion in 2018 , roughly $15 \%$ of the KSA's budgetary expenses, for health services and social development (Al-Hanawi MK, Khan SA, Al-Borie HM 2019). Despite these investments, the KSA, like many other nations, has increasingly faced concerns related to an aging population, a shortage of health services workers, and increasing health care costs. These increasing healthcare costs, in addition to potential changes to the economy, have led to a growing desire for cost containment strategies. To elucidate the relevant societal policies and context, the following sections offer an overview of the recent Vision 2030 campaign and its impacts on the healthcare system, a description of personnel and cost-related issues in the health sector, and some discussion of the KSA's approach to medical care.

Vision 2030

In 2016, Crown Prince Mohammad bin Salman announced the beginning of an aggressive plan to radically change the KSA in terms of how the country, heretofore, had operated. The name of this plan is Vision 2030, and its intent is to move the KSA beyond its dependence on oil by building a more diversified economy, a more robust society, and 
a more effective government. As one of the world's leading exporters of oil, the fortunes of the KSA have grown considerably over the decades. But what has begun to be recognized, both inside and outside the KSA, is that the oil reserves that the KSA has relied on to fuel its economic growth are beginning to diminish and at a pace more rapidly than had been anticipated. To address this, a major feature of this plan is the diversification of the Saudi economy away from a strict reliance on oil. How robust these diversification efforts will be to supplant the significant revenue achieved from the sale of oil is yet to be seen. More importantly, this raises significant concerns for programs and services, healthcare among them, that have been principally funded by oil revenues in the $\mathrm{KSA}$.

One of the central challenges faced by the $\mathrm{MOH}$ is funding health care services for all Saudi citizens (Country cooperation strategy for WHO and Saudi Arabia 20062011). As previously stated, the KSA had designated that healthcare is a right to be enjoyed by all Saudi citizens. And, because the total cost for public health services comes from the government and is free of charge, this has led, and continues to lead, to significant cost-pressure on the government; especially given how rapidly the population of the KSA has grown, the high price of new technology being used by healthcare facilities, and the growing awareness about health and disease among the community (Walston, S., Al-Harbi, Y., \& Al-Omar, B. (2008). For the most part, the ability of the KSA to provide free health coverage to its citizens was a direct function of the wealth of the KSA. 
An approach to cost containment within the KSA's healthcare system, and still a part of the Vision 2030 blueprint, is a rise in the use of health insurance. The genesis of health insurance in the KSA began with the establishment of the Council for Cooperative Health Insurance in 1999. The primary role of the Council was to introduce, regulate and supervise a health insurance strategy for the healthcare market in the KSA. The mechanics of the cooperative health insurance program involve 3 stages. Stage one is the application for cooperative health insurance in the private sector for both non-Saudis and Saudis alike. In this scheme, the employers of this group are the ones responsible for paying health care costs. Similarly, stage two mirrors the groups covered, the application procedure and the coverage. The main difference is that rather than the private sector paying for the coverage, it is the government paying since the individuals being covered are government employees. Hence, the major distinction here is that though all of the individuals are either Saudi or non-Saudi and they do receive healthcare coverage, the payers for that coverage depend upon for whom the employee works. This is not to detract from the KSA's pledge that healthcare for all Saudi's is a right. More to the point, it's simply sharing the burden for providing healthcare coverage between the government and private industry (Council of Health Services 2011).

Health Services Personnel, Costs, and "Saudization"

An integral part of the Vision 2030 plan is the overall restructuring of the country's healthcare system so that it is more representative of the citizens it serves, an approach called "Saudization", which aims to change the healthcare system such that 
more Saudi nationals are involved in the broad spectrum of health care services. The intended goal is a reduction in the overall cost of healthcare which, in turn, would reduce the strain on the $\mathrm{MOH}$ to continue to look to public monies to finance health care for Saudi citizens as it presently does. An additional goal is improved continuity of care.

As the nation's population of Saudis age, they are expected to place ever increasing demands on the country's healthcare system. Moreover, the shortages in health services graduates who are Saudis have generated concern within the MOH. The country's educational infrastructure has not been able to produce the necessary number of physicians, nurses, and healthcare technicians, even with the aid of financial investments and rapid industrialization. Despite exhaustive efforts to increase the number of Saudi doctors and nurses in the KSA, they currently account for only $17 \%$ of the total number of doctors and nurses in the country (KSA MOH 2020). Such shortages have led to a need to rely heavily on costly imported labor from a variety of countries. For example, one study revealed that nurses in the KSA came from over 40 countries including the United States, Canada, the Philippines and Australia (Walston, S., Al-Harbi, Y., \& AlOmar, B., 2008; Aboul-Enein FH 2002). This widespread presence of foreign nationals employed in the health service sector directly contributes to rising healthcare costs. As an example, the tenure of foreign nationals tends to be brief (approximately 2.5 years), and this turnover results in additional costs associated with new contracts and salary requirements. Additionally, there are often associated costs with the replacement of these workers as many negotiate new equipment and supplies as part of their contracts. These 
inefficiencies have led to increased costs to the Kingdom. Moreover, there exists in the KSA an overspecialization of physicians that results in a dearth of family medical practitioners and general internists. Simply put, the percentage of physicians in the Saudi healthcare system that practice family medicine is only 5\% (McKinsey Global Institute Report (MGIR) 2015). The reason for the imbalance in terms of family practitioners versus those who choose to specialize is sole due to the focus in the KSA of practicing curative medicine as opposed to preventative medicine. The presence of specialists has nothing to do with their pay. It has everything to do with the approach to medicine within the KSA. In the KSA a curative, rather than a preventative, approach to medicine is taken. Accordingly, more specialists abound since they each focus on a specific area of symptomology with the intent of curing the patient. In trying to change the approach to medicine in the KSA, the focus is shifting more toward practicing "preventative medicine"; hence, the need for more family practitioners.

Health Services Delivery and Approach in the KSA

Although the KSA deems healthcare an inalienable right of its citizens, that does not mean the accessibility, and even more importantly acceptability, to that healthcare is a given. In the KSA, the $\mathrm{MOH}$ oversees what is referred to as Primary Health Care (PHC). Moreover, as the major government provider and financer of health care services in the KSA, the MOH oversees a network of healthcare services comprising 244 hospitals, which provide 33,277 beds, and 2037 PHC centers (Almalki, Mohammed \& Fitzgerald, Gerard \& Clark, M. (2011). 
While healthcare within the KSA may be accessible for all Saudi citizens recent studies have shown that the acceptability of the current healthcare delivery approach is anything but acceptable. Evans, Hsu and Boerma (2013) point out that it is not only the accessibility, but also the acceptability to the PHCs that are critical to both the performance and evaluation of a healthcare system. Moreover, they point out that "acceptability is low when patients perceive services to be ineffective or when social and cultural factors such as language or the age, sex, ethnicity or religion of the health provider discourage them from seeking services" (2013, pg. 546). And as Fletcher (2000) has reported "patient satisfaction studies have been used to determine the acceptability among populations as well as the effectiveness of the [medical] service provided." (2000, pg. 13) In the KSA, a number of studies of the local healthcare service facilities concluded that patients in the KSA are not satisfied with the medical services provided by the PHCs (Al-Faris E, Khoja T, Falouda M, Saeed A, 1996; Ali MES, Mahmoud MEA, 1993; Al-Sakkak MA, Al-Nowaiser NA, Al-Khashan HI, AlAbdrabulnabi AA, Jaber RM, 2008; Mansour AA, Al-Osimy MH, 1993; Al-Qatari G, Haran D, 1999). The main reasons for dissatisfaction included the physical environment, waiting times, confidentiality measures, the location of centers, working hours, absence of specialty clinics, language and communication barriers and the waiting area structures. Additionally, "there is a gap between the professional knowledge of many PHC staff and their practical skills, with considerable costs for funding health care" (Mufti, M. 2004). 
This fact highlights a significant difference between the PHC model so prevalent in the KSA and the more contemporary Public-Private Partnership (PPP) model where cost absorption is secondary to the primary goal of providing best in class medical treatment. As Al-Hanawi \& Qattan (2019) point out, "From the public sector partner's perspective, the major benefit of the PFI or PPP is the private sector's capacity to absorb the risks of escalating costs. Transferring risk ensures that the physical health care infrastructure can continue to support services during an epoch of rapid technological, demographic, political, and epidemiological change.” (2019, pg. 5) As this pertains to healthcare in the KSA can be seen by the fact that Saudi citizens are not bounded by anything other than their ability to pay for the level of healthcare they want. People in the KSA choose the PHCs due to their affordability since medical treatment in the private sector is more expensive. But with this choice there is a hidden cost, and that is the determination of what medical treatments take priority.

Arguably, the KSA healthcare system has taken a more curative, rather than preventative, medical approach in treating patients. This fact tends to dovetail with the earlier discussion of the extent of overspecialization of medical practitioners at the expense of more family oriented general internists. But more apropos to the overall discussion of social support, and the focus on the burden of female caregivers in the $\mathrm{KSA}$, is the reality that in hospitals in the KSA certain diseases that fall outside the more common "disease pattern" tend to receive the least medical treatment. As Almalki, Mohammed, Fitzgerald, Gerard \& Clark (2011) point out, “The change in disease 
patterns from communicable to noncommunicable diseases in Saudi Arabia is another challenge that needs more attention from the $\mathrm{MOH}$. There has been an alarming increase in the prevalence of chronic diseases, such as diabetes, hypertension, and heart diseases, cancer, genetic blood disorders and childhood obesity. Treatment of chronic diseases is costly and may even be ineffective" (2011, pg. 791).

This view of chronic diseases likely represents a challenging context for those charged with caring for someone afflicted with a chronic condition. The reality is that within the KSA, "little attention has been devoted to informal caregivers" (Alrashed, 2017, pg.263). Alrashed continues, stating that, "informal caregiving in Saudi society is unrecognized. Women who provide informal care handle the responsibilities of their dependents, regardless of whether they are physically or financially able. Some may receive support from their social surroundings, whereas others must struggle on their own to fulfil this responsibility. Certain major attributes that have supported this process within the social context have begun to weaken." (201, pg. 270). While the KSA may recognize that all Saudi citizens are entitled to healthcare, this does not mean that all Saudi citizens receive the care, and support, that they need.

A Frame of Reference Regarding the Chronicity of Illness

The World Health Organization (WHO) defines health as a "state of complete physical, mental and social well-being and not merely the absence of disease or infirmity" (WHO 2011). At the opposite end of the spectrum, Eiser (1994) sees chronic 
illness as an illness in which "there is no available cure and the best that medical care can offer is relief from symptoms and the opportunity to participate in normal life as far as possible." (Eiser 1994). But within the definition of what constitutes a chronic illness there are different variations, each with a degree of exclusivity to the chronic condition being considered. And how each chronic condition is addressed and managed is a study in ad hoc responses for both the caregivers and the patients. For example, in the case of Sickle Cell Disease (SCD) there is the focus on managing the pain and pain crises. For asthma sufferers it is reducing the frequency of breathing attacks, while for epileptics it is closely monitoring and responding to seizures. Other chronic illnesses that require the same level of diligence, especially on the part of caregivers, include compromised liver function, cirrhosis, pulmonary artery dysfunction, metabolic disease, hypertension, Crohns disease, Fanconi syndrome, Cystic Fibrosis (CF), Diabetes, kidney failure, and Sickle Cell Disease (SCD).

The foregoing chronic illnesses were specifically selected to be studied because they predominate in the KSA. In all of these situations, the task of providing care is an enormous burden that is somewhat daunting for caregivers. (Raina et al 2005). Among the group of caregivers participating in this study, the patients under their care predominantly presented with the following chronic illnesses: Cystic Fibrosis (CF), Diabetes (DBS), Chronic Renal Failure (CRF) and Sickle Cell Disease (SCD). The discussion of SCD is expanded due to its prevalence among the population of the KSA. With regards to the other three conditions, their impact upon the caregiver is a distinction 
without a difference. In the case of CF, both Goldberg et al (1990) and Sawyer et al (1992) found that vis-à-vis parents who are not tasked with caring for a chronically ill child, the parents of a CF-afflicted child report demonstratively higher levels of stress. Moreover, and an aspect that is repeated when focusing on the caregiver role, mothers of CF-afflicted children report they are able to spend less time with their spouses. Mirroring the same approach to looking at how families with a CF-afflicted child functioned, two separate teams, Frank et al (1998) and Hamlett et al (1992) found a similar occurrence pertaining to parental care for the chronically ill child that was seen in families with a CF-afflicted child. Similarly, Standen et al (1985) found mothers indicated that not only were they tasked with shouldering more of the burden in caring for their chronically ill child, they also had less time to engage in activities with their child compared to those families where a diabetic child was not present.

\section{Sickle Cell Disease - An overview}

Sickle Cell Disease (SCD) is an inherited genetic blood disorder that limits the ability of red blood cells to transport oxygen in the body. SCD, along with the associated symptoms, can, and does, have widespread impact on both the psychological functioning of the individual diagnosed with the illness, as well as their families. The faulty red blood cells clump in blood vessels interfering with oxygen transport, a situation that results in intense pain. The condition can be systemic and lead to failure of other organs. Individuals with SCD have shorter life spans compared to the normal ones. (Platt, O.S., Brambilla, D.J., Rosse, W. F., Milner, Paul F., Castro, O., Steinberg, M.H., Klug, P. P., 
(1994). They need to be supported through the provision of medical care and wellness programs.

Worldwide, approximately 300,000 infants are born with SCD (Modell \& Darlison, 2008). In the KSA, with a population of roughly 33 million, information about the prevalence of SCD is patchy, but studies have reported that SCD is a relatively common genetic disorder in this part of the world. Unfortunately, although the prevalence of SCD has been decreasing in every region of Saudi Arabia, the prevalence remains higher than that in other countries. (Jastaniah, 2011). Moreover, SCD is endemic in southern and eastern Saudi Arabia, which indicates that current Saudi efforts to address this disease remain insufficient. The carrier status for SCD ranged from $2 \%$ to $27 \%$ (Alosaimi, 2017). These estimates of frequency are not based on newborn screening and probably underestimate the true frequency of SCD. In short, the greater focus on SCD is primarily due to the fact that Saudi Arabia faces numerous challenges in controlling SCD. One of the major challenges is the prevalence of consanguineous marriages ${ }^{3}(57.7 \%)$, and this prevalence can increase to $>80 \%$ in certain rural areas (El-Hazmi et al, 1995). As these marriages increase the risk of genetic diseases, the Saudi government is trying to educate people regarding the effects of consanguineous marriages through awareness

\footnotetext{
3 A consanguineous marriage is defined as a union between two individuals who are related as second cousins or closer. This includes unions termed first cousins, first cousins once removed and second cousins. It is estimated that one billion of the current global population live in communities with a preference for consanguineous marriage. Consanguineous marriage is traditional and respected in most communities of North Africa, Middle East and West Asia, where intra-familial unions collectively account for 20-50+\% of all marriages (Hamamy H. 2012)
} 
programs. But until programs such as these meet with widespread acceptance and implementation among the general populace, the risk of more genetic diseases will continue to be an issue.

Due to advances in clinical recognition, newborn screening, and therapeutic and preventative interventions, the mortality rates of children with SCD have decreased by approximately 53\% over the past four decades (Davis, Schoendorf, Gergen, and Moore, 1997; Yanni et al., 2009). Given that children with SCD are living longer, the psychosocial impact of the disease on the patient and their families becomes a more significant issue. Specifically, both children with SCD and their caregivers are at risk for significant psychosocial maladjustment (Edwards et al., 2005). To be sure, SCD is a condition that is debilitating, both to the sufferer and the caregiver. It involves intense and continuous medical care, pain management and psychological torture on the part of patients, parents, families, and caregivers.

Social support and family functioning for children with Chronic Illnesses The state of recent research into the issue of social support for families afflicted with Sickle Cell Disease (SCD) evidences that this a global issue. International studies provide proof that one of the key aspects of adequately being able to care for a family member stricken with this chronic illness is the quality and availability of social support for the primary caregivers (Keane \& Defoe 2016; Midence \& Shand 1992). Studies of other chronic illnesses have evidenced that when social support is available and in abundance to assist the caregiver, the caregiver's QoL also improves. Thus, ensuring a 
sound social support system for caregivers is a necessary element in achieving positive outcomes occurs for both patients and caregivers.

Caregivers of children with SCD and other chronic illnesses are burdened with missed work, increased family stress, and increased demands (Moskowitz et al., 2007). They are likely also tasked with the responsibility of managing their child's care, which potentially includes oversight related to preventative care, management of pain, teaching coping skills, and providing adequate nutrition/ hydration. Unfortunately, SCD primary caregivers often report a lack of support from both family and friends during their child's pain crises episodes, which further exacerbate and contribute to their feelings of anger, hopelessness, despair, helplessness, and frustration (Midence, Fuggle, \& Davies, 1993).

With respect to the QoL of caregivers, researchers have documented that the continued chronic stress of caregiving leads to an increase in allostatic load. For example, Dich et al. (2015) observed that caregiving predicted higher allostatic load and was linked to poor mental and physical health. While careful to point out that some degree of caregiving was beneficial, their findings suggested that those who reported the largest amounts of caregiving exhibited the highest levels of physiological dysregulation (Dich et al., 2015).

In sum, the management of chronic illness is dependent on robust social support systems. Great social support systems are grounded in educational institutions, marriage and family settings, and availability of funds. Researchers have found that countries with 
stronger social support systems and adequate medical care facilities positively influence the chronic disease burden (Reblin \& Uchino (2008: 4).

The scope of this literature review was focused on bringing into sharp relief the burden that caring for a chronically ill child places on a family. Those who are managing chronic illnesses face emotional, physical, financial, behavioral, social and personal sacrifices. For Saudi women in particular, this burden is likely intensified given norms that may encourage them to avoid seeking support for fear of appearing weak. In addition, they may encounter institutional barriers to care or health information given that they are unable to make medical decisions without consent from a spouse. Finally, shifting family structures may reduce the availability of extended family who might otherwise assist mothers of chronically ill children. 


\section{CHAPTER III: RESEARCH METHODS AND DATA ANALYSIS}

This dissertation seeks to explore and provide insight into the experience of female caregivers with chronically ill children and the level of social support afforded them. Specifically, two questions guided this research: 1) What is the experience of female caregivers with chronically ill children in KSA? and 2) What is the nature and availability of social support among these women? To address these questions, a combination of quantitative data collected via surveys and qualitative data collected through semistructured interviews was used. The following sections describe the study design, research questions, process of data collection, and the analytic strategy pursued.

\section{Study Design}

In the present study, a Chronic Illness Patient Caregiver Survey [see Appendix A] and semi-structured interviews [see Appendix B] were used. The Caregiver Survey was designed to elicit demographic information and provide a standardized indication of the overall health status of the caregivers.

Semi- structured, in-depth interviews were selected because of the depth of information that may be obtained and the ability to capture participants' feelings and thoughts. An interview guide was developed to ensure that all of the participants were being asked the same questions, thus making the coding process easier and more reliable. But, the semi-structured format also enabled the PI to probe with more open-ended indepth questions, which turned out to be a major strength of this research. The interview guide focused on the level of social support that has been provided to caregivers, as well 
as information about the Quality of the Caregiver's Life ("QoL"). Collectively, and based on the nature and goals of this research, these two research tools provided the necessary qualitative research to complete this study.

\section{Research Questions}

Research Question 1: What is the experience of female caregivers with chronically ill children in KSA? To address this question, several indicators were used to indicate quality of life and caregiver's health. Two questions were chosen from the selfrated health scale (SF-36) and were included in the survey in order to capture the overall health for the caregivers. One asks them to rate their health in general, while another asks the participant to compare their health to the previous year. Interview questions designed to elicit responses on this topic included: (1) "Can you tell me about your feeling when you first learned about your family member's condition?” (2) “How do you cope with feeling like this?" or (3) "Has your relative's condition affected any relationships in your family? If so, how?". Questions in the interview guide further inquired about impacts to the caregiver's relationships, employment, and health habits (e.g. sleeping habits, eating habits, and activities).

Research Question 2: What is the nature and availability of social support among these women? This question was addressed in the interview guide with a series of questions concerning the perceived level and what kind of support was provided by family members, friends, and relatives. Questions were also included on how satisfied the 
participants were with this support. These questions were taken from the Duke Social Support and Stress Scale (DUSOCS).

Additionally, surveys collected their demographic information, household structure, and time spent engaged in caregiving activities. The survey and the interview guide were both designed to provide details about the nature of caregiving, the women's thoughts on QoL issues, and the level and importance of social support to the overall wellbeing of the caregiver. Moreover, this qualitative instrument incorporated known measures of the aforementioned concepts from existing interview guides on similar studies conducted in the UK.

Site Selection

The site selected for this research study was the King Fahad Medical City (KFMC) complex located in Saudi Arabia's capital Riyadh. With a total capacity of 1200 beds, KFMC has a strategic location in the heart of Riyadh. Patients from all over the region are referred to KFMC for a variety of treatment regimens that draw upon the diverse medical and professional specialties of KFMC. For the most recent year, approximately 30,000 inpatients and 500,000 outpatients sought medical treatment at KFMC.

Comprising KFMC's four major hospitals are the Main Hospital, the Children's Specialized Hospital (the hospital the PI chose to conduct her study), the Women's Specialized Hospital, and the Rehabilitation Hospital. The PI conducted her research in the Children's Hospital because this is the primary care facility where the respondents 
with chronically ill children would take them to be seen by the medical staff. Previously it was discussed that the medical community in the KSA takes a curative approach as opposed to a preventative approach in the practice of medicine. These four hospitals fit within the paradigm of being hospitals offering primarily specialty medical services. For example, Main Hospital is a specialized surgical, critical care, and oral/maxillofacial surgical center. Additionally, this hospital contributes to the health education and teaching at the local level in addition to enhancing the treatment of diseases through medical research and specialized medical training programs. Similar to the Main Hospital, the Children's Specialized Hospital was previously one of the biggest hospitals in the region, providing various specialized clinical programs and intensive medical care services geared to pediatric patients. The Women's Specialized Hospital is one of the KSA's tertiary hospitals providing primarily specialized medical care in OBGYN. Finally, the Rehabilitation Hospital is the only Ministry of Health (MOH) hospital providing acute holistic rehabilitation services to referred patients through an interdisciplinary rehabilitation program. It is the first hospital affiliated with the $\mathrm{MOH}$ to provide comprehensive rehabilitation services for both newly injured and existing patients who need therapeutic and rehabilitation treatments. The hospital is also the first medical institution outside North America to obtain CARF Accreditation, after CARF conducted a full survey of all rehabilitation services over the course of two years. Today, KFMC is a CARF member and officials from the Rehabilitation Hospital take part in the assessment of EU and US hospitals. 


\section{Participants}

The participants for this study were screened with the assistance from the King Fahad Medical City’s Chairperson for Childrens Specialized Hospitals Research Committee, Dr. Abdulrahman AlHussaini, and the head of the hospital's Social Services Department, Dr. Nourah AlSubaie. Once the PI had made her introductions with both Drs. AlHussaini and AlSubaie, a caseworker and nurse were assigned to assist and facilitate the PI's efforts to meet and solicit each caregiver's participation in the study. Once the social worker and nurse were assigned to the PI, the PI was taken to the ward in the hospital that was designated as the ward primarily charged with the care and treatment of children with chronic illnesses. On the ward, the caseworker accompanied the PI to each room where an introduction was made and the scope of the study was discussed with the caregiver to ensure that they understood what was involved and how important the study was. Each caregiver was then provided with a consent form to complete and sign indicating their willingness to participate in the study. All interviews and surveys were administered by the PI with the oversight of both the caseworker and a nurse. The semi-structured interviews and survey were restricted to female caregivers of children suffering from a chronic illness. To participate, women had to be older than 18 years of age and they must have and/or care for a child, affected with chronic illness, who was a current patient at the King Fahad Medical City, between July 20 and August 20 of 2018. Non-Arabic speaking caregivers were excluded from the study, as well. For the caregivers that agreed, accommodations were made to have both the survey and the 
interview completed and conducted in a private room. The PI interviewed 35 female caregivers who have children currently afflicted with chronic illness such as Cystic Fibrosis (CF), Diabetes (DBS), Chronic Renal Failure (CRF) and Sickle Cell Disease (SCD). In addition to participant interviews held at KFMC, the surveys and semistructured interviews were also conducted at the inpatient and outpatient clinic where caregivers had brought their children for an appointment to see a doctor.

Data collection

Data was collected using in-depth interviews guided by a semi-structured interview guide as well as survey (see appendix A). A convenience sample of participants was selected for the survey and interviews. The mothers were encouraged to participate by appealing to their sense of urgency in advancing policies that will not only benefit them, but also future mothers of children afflicted with a chronic illness. The PI secured an IRB approval (approval \#s 18-337E and H-01-R-012) from the KFMC prior to conducting the research. The caregivers who agreed to participate in the study signed the required consent form. The consent form emphasized that respondents did not have to answer any question if they chose not to, and that they were free to stop the survey at any time. They were also told that all responses would be kept confidential. The surveys and semi-structured interviews were also conducted at the inpatient and outpatient clinic where caregivers had brought their children for an appointment to see a doctor. The nurse assisting the doctor served as the PI's proxy assistant by asking each caregiver if they wanted to participate in the study. For the caregivers that agreed, accommodations 
were made to have both the survey and the interview completed and conducted in a private room. Both the surveys and semi-structured interviews took place inside the hospital where both the caregivers and their children were present.

After providing the required disclosures to the participants in-person, the PI administered a written survey that consisted of questions pertaining to the frequency of medical visits by the patient, the frequency with which the caregiver accompanied the patient, the length of time on a daily basis the caregiver took care of the patient, as well as other questions that elicited information regarding the participants' demographic information and overall health status as caregivers. This process took an average of 15 minutes to complete.

Immediately after completing the survey, the participants were interviewed by the PI. A semi-structured interview guide was used during the entire interview which lasted between 30-45 minutes. As with the survey and interview conducted in the hospital setting, the participants at the clinic adhered to the same protocols of signing the required disclosures and consent forms. Caregivers were then interviewed by the PI in the same private room where the patient slept, which is also where the caregiver slept while the patient was in the hospital. Providing the participants access to a private room, in which to both complete the survey and be interviewed, was a critical component for this study as it served to put the participants at ease given the sensitive nature of the issue being discussed. In fact, the literature on conducting semi-structured interviews underscores the importance of setting as an integral part to evoking the most honest response from the 
participants being interviewed. Scholars have indicated that if others are within hearing distance of interviews that it can create tension as well as impact what can or will be discussed and that this may be addressed by finding suitable spaces to conduct research (Edwards and Holland 2013). Simply put, providing a secure space in which to interview the participant ensured the most relaxed atmosphere available to ensure a completely candid and honest response to questions posed by the PI.

Equally as important to ensuring privacy and confidentiality by conducting interviews in a secure space was both the gender and cultural identity of the PI. Being both female and an indigenous member of Saudi Arabian society, the PI was uniquely positioned to not only understand the cultural stress the caregivers were experiencing, but also uniquely equipped to understand Saudi Arabian cultural norms, language and customs. Given the PI's background, she was uniquely equipped to be able to establish both trust and rapport with the participants quickly and to such a degree that the participants felt more at ease and appeared more willing to discuss their experiences as caregivers. All interviews and surveys were administered by the PI with the oversight of both a caseworker and a nurse, both of whom were provided by the hospital.

Data Analysis:

The semi-structured interviews and the survey were transcribed and translated by the researcher. Each interview was assigned a pseudonym, organized, and saved in password protected Microsoft Word documents in multiple places to ensure both the safety of the data and confidentiality of the respondents' identities. The data was then 
analyzed by using Dedoose software. Initial coding was conducted according to the interview guide which highlighted some of the following emerging key themes: family routine, family conflict, social support, and activity limitation. These themes were finalized once the data analysis was completed. Subsequent steps involved focusing on (1) the most common and surprising codes analyzed, and (2) the social support themes required to develop subcategories that provide further understanding of the type of social support mothers receive. The goal in analyzing these codes was to be able to answer the main research questions, namely "What is the experience of female caregivers with chronically ill children in KSA, and (2) What is the nature and availability of social support among these women?" The PI used memos during the coding process to facilitate improving the coding and analysis. 


\section{CHAPTER IV: FINDINGS}

The focus of this study has been to explore the quality of the caregivers' lives (QoL) and the level of social support afforded them. In order to address these issues, codes or themes were formulated that not only aided in guiding the interviews with the participant, but also served to provide a foundation to better understand the concepts of QoL and Social Support and provide the appropriate treatment for each concept. Two primary themes comprise this section of the paper: The quality of life $(Q o L)$ of the caregiver and the level of Social Support that was available to each caregiver (based on her own perceptions). Further comprising each theme are a series of sub-themes designed to flesh out the nuances of each caregiver's response that, when taken together, give an accurate composite of what the life of a caregiver is like under the burden of providing, in some cases, over 16 hours of palliative care on an average day. The first six sub-themes or codes were derived from responses related to the caregivers' QoL while the remaining five sub-themes emerged based on responses about women's experiences with the Social Support that is afforded them. Themes and sub-themes are listed below.

\section{CAREGIVER'S QoL}

1. CAREGIVER'S HEALTH

2. SOCIAL LIFE AND ACTIVITY LIMITATION

3. FAMILY RELATIONSHIP

4. BURDEN OF CAREGIVING AND ABILITY TO COPE

5. FUTURE OUTLOOK 


\section{$\underline{\text { SOCIAL SUPPORT }}$}

1. FORMAL SOCIAL SUPPORT

2. INFORMAL SOCIAL SUPPORT

3. SOCIAL SUPPORT - RELIANCE UPON AND UTILITY OF

4. INFLUENCE AND OCCURRENCE OF CULTURAL PRACTICES

5. CAREGIVER'S NEEDS AND WANTS

The focus of this research was to examine the experiences of female caregivers in the KSA and determine the extent to which they enjoyed access to social support such that their caregiving burden was ameliorated. In accordance with the first question, the researcher looked specifically at the elements of physical and psychological stress endured by the caregivers. Additionally, considered were various aspects of the caregivers' lives that were affected such as limitations on their activities and their own ability to maintain their own lives in terms of general health such as proper nutrition and exercise. The second question explored the issue of social support experienced by the caregivers, including how available it was and what types of social support it was, such as formal vs. informal social support.

The results are organized in two major sections. The first section offers a quantitative analysis of the women's responses. Survey data provided standardized responses to questions on self-rated health, time spent engaged in caregiving activities, impacts to daily life and activity limitations, and sociodemographic information. These responses are summarized in what follows. In the next chapter (Chapter V), the qualitative results are described and are organized based on the two primary themes of 
Quality of Life among female caregivers and on social support, which are further organized on the basis of sub-themes.

\section{Quantitative Results:}

All the participants in the study were female. In accordance with Saudi customs, when the caregiver is accompanying her sick child who is admitted to the public hospital, the caregivers should have a female companion. This is to ensure that the families' need for privacy for their women and children is not violated. Moreover, during any overnight stays at the hospital the caregiver is not permitted to have her husband in the same room as she and her ill child. Therefore, the caregiver is not able to switch off the responsibility of caring for their child with her husband during the night. Because of these norms, the female caregiver must find other females to assist her with this job. The private hospital may have less restrictive rules, however.

All of the participants live with the patient. Moreover, a majority of the participants said that the treatment for their ill child is paid for by the Saudi government. Some of the participants who reside outside of Riyadh and have to fly to the hospital indicated that the hospital provides free air transportation for the mother, her child and for the mother's guardian. Despite the free treatment and transportation assistance, some of the participants indicated that though their airline ticket was paid for, they were still obligated to cover their temporary housing and transportation costs while they were within the city of Riyadh. These additional costs ranged between approximately 600 and 4000 Riyal (\$162 to \$1080) for one year. Of the universe of participants interviewed for 
this study, only 15 were not subjected to covering these additional costs. The participants who answered this question and provided the specific amount of out of pocket costs that they had to absorb were not necessarily negatively affected by this cost. Rather, they answered the question because it was part of the survey.

\section{Table 1.}

\begin{tabular}{|l|l|l|}
\hline Participant Demographics & Number & Percentage \\
\hline Relationship to Patient & & \\
Mother & 30 & $85.7 \%$ \\
Sister & 2 & $5.7 \%$ \\
Grandmother & 2 & $5.7 \%$ \\
Aunt & 1 & $2.9 \%$ \\
\hline Age & & \\
$21-35$ & 14 & $40 \%$ \\
$36-45$ & 13 & $37.2 \%$ \\
46 or more & 8 & $22.8 \%$ \\
\hline Education & & \\
High School or Less & 19 & $54.3 \%$ \\
Two years degree & 2 & $5.7 \%$ \\
University or more & 14 & $40 \%$ \\
\hline Marital status & & \\
Married & 25 & $71.4 \%$ \\
Widowed & 2 & $5.7 \%$ \\
Divorced & 5 & $14.3 \%$ \\
Single & 3 & $8.6 \%$ \\
\hline Employment & & \\
Yes & 8 & $22.9 \%$ \\
No & 26 & $74.2 \%$ \\
Retired & 1 & $2.9 \%$ \\
\hline Area of Residency & & \\
Central Region & 19 & $54.3 \%$ \\
North Region & 5 & $14.3 \%$ \\
South Region & 5 & $14.3 \%$ \\
Eastern Region & 4 & $11.4 \%$ \\
Western Region & 2 & $5.7 \%$ \\
\hline & & \\
\hline
\end{tabular}


The data above clearly indicates that the majority of primary caregivers are mothers. However, two participants were older female siblings of the child with a chronic illness, two were maternal grandmothers, and one was the child's aunt. In cases where the father takes care of a sick child, there is always the presence of a female family member, which is typically the father's mother or his sister.

Most women were between the ages of 21-45 (77.2\%). A majority of the participants have a high school education or less (54.3\%) and many evidenced a low rate of literacy. The remaining participants' education ranges from a two- year degree to University studies or more, which reflects the increasing emphasis on access to education for females.

Most of the participants are married (71.4\%), which is an essential part of the Saudi culture. Yet, it is noteworthy that of the total, 14.3 percent of the participants are divorced. Although studies are limited, according to a report by Selena Rincon, "the causes for divorce are very similar to those in other parts of the world, such as infidelity and domestic abuse. The difference today is that it is easier to divorce even if it is still perceived negatively. Women, especially, have more resources to pursue a divorce" (2019, Pg.1). Moreover, according to the Saudi Ministry of Justice, "the total divorce deeds reached 51,125 in 2019 which decreased about 11.93\% from 2018” (Saudi Ministry of Justice, 2019). Saudi culture would suggest that an inability to engage in caring for an ill child is the predominant cause of divorce. 
Employment is a crucial part of an individual's participation in home care duties. The findings reveal that $74 \%$ of the participants are unemployed. The failure to participate in active employment is likely attributable to the low rate of literacy among many of the participants which explains, in part, their lack of achieving higher education.

Though the researcher aimed to involve participants from each part of Saudi Arabia, all the participants were from urban area but one of the participants indicates that she is from rural area located in Hail (Eastern Region). However, most of the participants are from Riyadh.

Table 2.

\begin{tabular}{|l|l|l|}
\hline Family Demographics & Frequent & Percentage \\
\hline Family Size & 6 & \\
$3-4$ & 15 & $17.1 \%$ \\
$5-6$ & 14 & $42.9 \%$ \\
7 or More & 25 & $40 \%$ \\
\hline Type of Family & 5 & $71.4 \%$ \\
Nuclear Family & $5 x+1 \%$ \\
Extended family & 5 & $14.3 \%$ \\
\hline Single parent family & 6 & $14.3 \%$ \\
$1-2$ & 18 & \\
$3-4$ & 5 & $17.1 \%$ \\
$5-6$ & 6 & $51.5 \%$ \\
7 or more & 29 & $14.3 \%$ \\
\hline Number of Sick Children & 6 & $17.1 \%$ \\
1 & & \\
2 or more & & $82.9 \%$ \\
& 7 & $17.1 \%$ \\
\hline Number of workers in the family & 20 & \\
No one works & 7 & $20 \%$ \\
1 & 1 & $57.1 \%$ \\
2 & & $20 \%$ \\
3 or more & $2.9 \%$ \\
\hline
\end{tabular}


Table 2 above presents a summary of family demographics of the caregivers. The table shows various details about family structure and how it is organized. According to the results, $42.9 \%$ of families have between 5 and 6 members, while $40 \%$ of the families have 7 or more members. Only $17.1 \%$ of the families are composed of between 3 and 4 members. However, the predominant family structure is that of the nuclear family, $71.4 \%$ vs $14.3 \%$ who indicated that they lived in an extended family setting. This finding is in line with what scholars (e.g. Obaid 2015) have observed. Specifically, prior research has indicated a decline in the extended family structure and an increase in the nuclear family model.

The above data also reveals that half of the families (51.5\%) reported 3-4 children, while only $17.1 \%$ had 1-2 children. Interestingly, the same percentage of families choosing to have the fewest number of children also was the same percentage that opted to have the largest percentage of children, reporting 7 or more children residing in the household. The minority $(14.3 \%)$ had 5-6 children. The number of children directly dictates the size of a family and, therefore, subsequent economic expenditure.

The data indicates that $82.9 \%$ of the families acknowledged having at least one child who is sick with a chronic illness such as SCD, Kidney, Diabetes, Liver, Cancer, Cystic fibrosis, respiratory diseases, digestive diseases, or Heart disease. The remainder, $17.1 \%$, had 2 or more sick children. One respondent reported to have 5 children of which 3 were suffering from SCD. The age of these children was between 3 months to 14 years 
old. The study also revealed that $57.1 \%$ of the families, which is the highest percentage, had a single individual working to earn a living. In most cases, these were males who were the heads of their families. Twenty percent of the families did not have any person working and were completely dependent upon the government for support. Another $20 \%$ of the families reported having two workers, while the remaining $2.9 \%$ had 3 or more family members working.

Table 3.

\begin{tabular}{|l|l|l|}
\hline Caregivers Health & Frequent & Percentage \\
\hline Health in general & & \\
Excellent & 8 & $22.9 \%$ \\
Very good & 8 & $22.9 \%$ \\
Good & 12 & $34.3 \%$ \\
Fair & 4 & $11.4 \%$ \\
Poor & 3 & $8.6 \%$ \\
\hline Health Compared to one year ago & & \\
Much better & 6 & $17.1 \%$ \\
Somewhat better & 6 & $17.1 \%$ \\
About the same & 10 & $28.6 \%$ \\
Somewhat worse & 9 & $25.7 \%$ \\
Much worse & 4 & $11.4 \%$ \\
\hline Type of caregiver's diseases & & \\
No disease & 14 & $40 \%$ \\
One or more diseases & 21 & $60 \%$ \\
\hline Time spent caring for patient on a daily & & \\
basis & & \\
Less than 4 hours & 7 & $20 \%$ \\
4 hours & 4 & $11.4 \%$ \\
8-16 hours & 5 & $54.3 \%$ \\
More than 16 hours & 19 & \\
\hline
\end{tabular}

The health of primary caregivers is a fundamental aspect that was analyzed in this study. In table 3, the respondents' perceptions of their own quality of health were as follows: $34.3 \%$ of the respondents believe that their overall of health is good, $22.9 \%$ 
believe their overall health is very good while a similar percentage also feel that their health is excellent. Only $11.4 \%$ believe that their health is fair, while the remaining $8.6 \%$ consider their health to be poor. Apparently, the majority of the respondents are satisfied with their health, while a minority has a view that their health is not doing well. The respondents were also given the opportunity to compare their health currently with what it was a year ago. The majority (28.6\%) believe that their health is the same and nothing has changed, while $17.1 \%$ believe that their health is much better now compared to how it was a year ago. Additionally, another $17.1 \%$ believe that their health is somewhat better than a year ago, implying a slight improvement, while a total of $37.1 \%$ believe that their overall health has deteriorated over the past year. However, when the participants were asked what illnesses they had, about $60 \%$ of the caregivers indicate that they have one or more diseases such as diabetes, hypertension, Heart disease, high cholesterol, anxiety and depression; which potentially suggests an increased risk of preventable illness. The remaining $40 \%$ of caregivers said that they do not have any disease. Importantly, it was observed that $54.3 \%$ of caregivers spend more than 16 hours caring for patients on an average day. Only $20 \%$ spend less than 4 hours each day caring for patients, $11.4 \%$ of the caregivers strictly work for 4 hours, and the remaining $14.3 \%$ working between 8 and 16 hours a day. These findings suggest a significant time-related burden among female caregivers in the sample. 


\section{CHAPTER V: QUALITATIVE FINDINGS}

Two primary themes comprise this section of the paper: The QoL of female caregivers in the KSA and the level of Social Support that was afforded each caregiver. The results for each of these themes are presented in each of the next two sections. Within each of these two themes there are a series of sub-themes. Comprising the Caregiver's QoL are the following six codes: Caregiver's Health, Activity Limitation, Family Relationship, Social Life, Burden of Caregiving and Ability to Cope, and The Caregiver's Future Outlook. Comprising Social Support for the caregivers are the following five codes: Formal Social Support, Informal Social Support, Social Support Reliance Upon and Utility Of, Influence and Occurrence of Cultural Practices, and the Caregiver's Needs and Wants. The findings, based solely on the participants' answers to interview questions posed by the $\mathrm{PI}^{4}$, are summarized and organized below.

\section{Theme 1: Caregiver's Quality of Life:}

Broadly speaking, the quality of the female caregiver's life is one marked by enormous stress that ebbs and flows with the different cycles of health crises their sick child exhibit. Whether it is the pain crises of SCD, asthmatic attacks of asthma or the episodic panic attacks of a CF child who feels that they are drowning in their own phlegm, the caregiver's day to day existence is marked by stress and more stress. For many of the participants the stress began the moment they were apprised of their child's

\footnotetext{
${ }^{4}$ In lieu of presenting the Participants' quotes in the actual discussion of the findings, a representative sample of both the interview questions and the Participants' responses are detailed in Appendix C.
} 
condition. From that point forward the mothers interviewed said that they were sad, destroyed inside, given to constant crying and worrying, and thinking in more catastrophic terms rather than marshalling their inner strength to figure out how to deal with the new normal of a life now dictated by caring for a chronically ill child. On a daily basis, the routines of caregivers who are tasked with caring for a chronically ill child upwards of 16 hours a day include not only caring for the child, but also addressing the domestic chores of that are expected of them. If the caregiver is at the hospital, the only thing they do is take care and look after the sick child. If they are at home they are responsible for all of the house duties (cleaning, laundry, cooking), as well as looking after their other children, their husband, plus the sick child if the child is at home. If they are educated they help their kids with school. Women can depend on their daughters to assist them if they're old enough, but rarely can depend on a housekeeper even if they can afford one.

A common complaint among the women interviewed surrounded the manner in which they were informed of their child's illness. Many reported that rather than having news delivered with sympathy and some guidance as to what they do next, the diagnosis was presented in a clinical fashion, meaning it was perceived as efficient and with little detail. The women perceived that there was little evidence that medical staff were concerned with how the news was received, and the level of detachment the medical staff exhibited in dealing with the participants led many to indicate that their emotional state was very fragile after the encounter. In some cases, the receipt of the diagnosis 
exacerbated an underlying condition that the caregivers themselves already suffered from such as depression.

Interestingly, caregivers who were someone other than the mother of the ill child did not report any associated stress with how or from whom the news of the child's illness was delivered. Of the universe of caregivers interviewed, $14.3 \%$ fell into this category and were either a close family member such as a sister, an Aunt, or grandmother. Moreover, this same group of caregivers usually spent less than 4 hours per day acting as caregiver. Not surprisingly, they indicated that they were neither affected physically by acting as the caregiver, nor did they seem to manifest any mental or emotional issues with having to care for the ill child.

Though social support is fully explored in a later section, it is worth mentioning here that all of the participants indicated that going for a visit and meeting other people, such as those in their circle of friends added immeasurably to improving their outlook and, hence, their quality of life. While each of the participants agreed that altering their current circumstances such that their child was no longer sick was beyond their control (an indication of the acceptance of predestinational thinking - (please see page 57 for a more detailed discussion of the concept of Predestination)), many communicated that the mere altering of their physical surroundings and interacting socially with others provided a way to release the pressure that they were experiencing. In effect, just being able to remove themselves from all evidence of the burden that they had to live with daily was incredibly important. 
It should be noted that not all of the caregivers interviewed felt the overwhelming pressure that the other caregivers felt. In fact, for approximately $42.8 \%$ of the caregivers, they said that caring for their sick child did not affect them. Asked to qualify this, these caregivers remarked that "it depended upon both the age of the child and the severity of their illness". If the child being cared for was older than 5 years of age and his disease was not especially serious, then the caregivers were more than likely not affected. Accordingly, the caregivers in this group did not feel a compulsion to get away from their circumstances to interact socially outside of the home.

Caregiver's Health:

The caregiving burden manifests itself in two distinct ways among female caregivers in the sample: physical stress and emotional/mental fatigue and anxiety. When it came to discussing the nature of the illness of the family member for whom the caregiver was caring, one constant reaction echoed by all of the caregivers interviewed was that they were filled with despair and resignation: despair over their current situation and that of their ill family member, and resignation that their best coping mechanism was to accept the circumstances as preordained by the will of Allah. In fact, Al-Shahri (2002) states, “... a fundamental doctrine in the Islamic faith [is] people believe in predestination and attribute the occurrence of disease to the will of Allah" (2002: 134). Al-Shahri qualifies this statement by pointing out that "the belief in predestination does not seem to prevent Saudis from seeking medical treatment or utilizing readily available preventative services such as childhood immunization programs" (2002: 134). The belief in 
predestination aside, the reaction to their situation by an overwhelming majority of the participants was less than positive. Indeed, the saying that the caregiver is the second patient is very apropos when it comes to characterizing the participants of this study.

As mentioned in the previous chapter, more than half of the caregivers interviewed suffer from one or more chronic illnesses, and the information obtained in interviews reflected the deleterious impact that their caregiving duties had on exacerbating their already comprised health. As it was previously noted, Benner (1985) discussed the connection between the body and the mind, and the pivotal role that chronic stress plays in further exacerbating not only the caregiver's health, but also their ability to keep from becoming a patient themselves. Most of the chronic illnesses afflicting the caregivers were illnesses due to stress, anxiety and/or exhaustion.

Another indicator of the impact of caregiving among these women is reflected in an inability to ensure basic self-care. For example, many reported problems maintaining a proper diet, exercising moderately, or even making sure they keep their own medical appointments. Some of the participants openly acknowledge that they have either delayed medical appointments for themselves or have simply refused to acknowledge that they are, in fact, ill. It is likely that the reason for this is that within the KSA, there is a strong cultural emphasis that the matriarch is the one who takes care of the children, whether they are ill or not. This is an implicit understanding that Saudi men and women, husbands and wives, have. This is traditionally how Saudi culture, with respect to gender breakdown in terms of familial responsibilities, has been carried out. More specifically, 
Saudi husbands are the de facto breadwinners and Saudi wives are the de facto rearers of the children in the family. In this regard, nobody can replace them when it comes to the task of taking care of their children.

Many of the women expressed issues related to lack of sleep or exhaustion. It was pointed out earlier that most of the caregivers were spending more than 16 hours per day caring for their sick family member. That level of care and concern does not end once the ill family member enters the hospital. Once the ill family member is admitted to the hospital, the caregivers often reported remaining with their sick child and continuing the cycle of worry. Further exacerbating this is the reluctance of the caregivers to sleep, let alone even nap, during the day for fear that they will miss crucial information dispensed by the doctors.

This lack of sleep also affects how the caregivers feel physically, particularly in terms of their capacity to deal with actual physical pain associated with performing nonstop caregiving. Sarafis et al (2016) studied the impact of caring for patients from the perspective of trained nurses whose job is to care for a multitude of patients on a daily basis. Though the number and variety of patients differs from the unique one patient focus of the caregivers in this study, the parallels in the symptomology of pain experienced by the nurses parallels that of the caregivers herein studied. According to Sarafis et al, "As far as physical health is concerned, the results confirm the literature evidence, in which work-related stress correlates with many physical health problems including migraines, muscle, back and joint pain, long term physical illnesses, 
hypertension, irritable bowel syndrome and duodenal ulcer and immune and endocrine system illnesses" (2016: 7) The complaints from the nurses in the Sarafis study mirror the same complaints voiced by the caregivers.

The acute physical issues experienced by the caregivers were further aggravated by their persistent lack of interest in eating. Forty-five percent of the caregivers said that their appetite was affected due to either their general poor mental health or because they also suffer from a chronic condition that severely impairs their desire to eat. The loss of appetite experienced by the caregivers not only negatively affected their ability to provide a high level of care for their ill children, it also played a role in negatively impacting the health of their spouse. Not only does the Saudi culture place a premium on the ability of a Saudi mother to expertly care for her children, it also places a premium/demand/requirement that the Saudi wife expertly take care of her husband's needs. And one of these needs is to cook for her husband. With their appetites suppressed due to anxiety, untreated underlying health issues and simple exhaustion, the female caregivers studied also felt that they fell short of being able to execute some of the basic things a Saudi wife is expected to do. Though some of the participants indicated that they occasionally had relative who could help out and cook a meal or two for their husbands (further discussed in the section dealing with Social Support), this still did not alleviate the stress that the caregivers felt from not being able to handle a relatively straightforward task. However, this kind of support made the caregivers pleased and relieved 
In addition to the greatly reduced amount of sleep and a drastic cutback in caloric intake, the caregivers also had to deal with stress and pressure of shouldering the caregiver burden by themselves. How this physically affected the participants was that it allowed for an undiagnosed chronic condition to surface, and in some cases for two undiagnosed chronic conditions to present. Of the participants in the study, $60 \%$ indicated comorbidities for conditions such as diabetes, hypertension, and cardiovascular anomalies. A singular finding is that of one participant who acted as the caregiver for her sister's ill child. Having a heretofore unremarkable medical history, upon taking up the caregiving responsibilities for her sister, this participant developed high cholesterol concurrent with an acute anxiety disorder the consequences of which led her to discontinue her university studies.

During the interview, the participants were asked to comment on other physical manifestations of the stress and strain that they had to endure to simply execute their caregiving duties. Aside from the exhaustion from lack of sleep already discussed and their negligence toward maintaining their own health, all the participants indicated some form of physical ailment directly associated with caregiving. The ailments listed included muscle cramps, lower back pain, joint pain in the shoulders, knees, elbows and wrists, and lower extremities edema. The issue of the participants' loss of appetite was already discussed, but what is worth mentioning is that during the occasions when the caregivers were fully engaged in caring for their ill children, they became more mindful of what not only their children ate, but what they themselves consumed. And though all 
the participants indicated that they suffered a loss of appetite, they did say that when they were hungry, they gravitated toward eating more nutritious foods and meals. Asked how this change in diet compared to the time before their child became ill, the participants indicated that the selection of more nutritious foods and even organic foods was a direct effort to focus on doing more things that were healthy so as to set an example for their ill child to see so that they, too, would focus on more healthy eating.

Quality of Life can be assessed based on several aspects. Given the observed sacrifices to amount of sleep and eating habits, they are evidencing a Quality of Live (QoL) that is not only not optimal, but severely deficient (George and Bearon 1980). Moreover, and as the following section on Activity Limitation emphasizes, the degree to which physical function, mental status, and engagement in normative social interactions has been compromised, so, too, has their overall QoL.

Activity Limitation:

Similar to the findings among the caregivers studied with respect to the negative physical effects that they suffered due to their caregiving burden, the participants also spoke in unison as to how severely restricted their activities had become because of their caregiving duties. What ranked among the activities the group missed the most was being able to relax, visiting with friends and simply enjoying their time outside of the house. While these types of activities were missed the most by those participants with more discretionary time on their side, the segment of the participant pool who felt especially frustrated and upset were those participants who previously had employment outside the 
home or were completing additional education to advance their careers. For these women, role of caregiver meant giving up these pursuits. The qualifier for the group as a whole was that the degree their activities were limited was directly related to the severity of their child's disease. Accordingly, if their child's disease was not as bad as initially diagnosed or if the caregiver was resourceful enough to craft a strategy that allowed an accommodation in her life to actively care for her sick child and still do the things she wanted, then these caregivers were better able to live a more normal life.

Family Relationships:

As Moskowitz et al (2007) pointed out, caregivers of children with a chronic illness, in particular family members, are burdened with missed work, increased family stress, and increased demands due to the unpredictability of how the chronic illness manifests itself thereby exacerbating the patient's condition (Moskowitz et al., 2007). Every participant interviewed echoed what Moskowitz reported. Many of the participants found themselves skipping events and family gatherings. Stress between them and their husbands was reported to be more than usual, and manifested itself as depression and anxiety, as well as frequent mood swings. Some women reported concerns that stress between the couple might result in the husband deciding to leave and spend time at a different residence.

This further exacerbated the burden experienced by the caregiver for now she felt some resentment that she was not being fully supported by the husband in doing what, culturally speaking, she was expected to do. For some of the participants, this confused 
them and left them furthered burdened because not only did they not have anyone to talk with about their feelings of caring for an ill child, but they also now had to deal with marital issues and didn't have anyone to discuss these issues with either. The end result was that the overall stability of the family was put in jeopardy and, in some cases, both parents decided to divorce. In some cases, however, the result of this added stress is that it brought couples closer together. Although, culturally speaking, women in the KSA generally defer to their husbands in terms of leadership within the family, especially when it comes to financial matters, and likewise Saudi husbands defer to their wives when it comes to the welfare of the children, unusual circumstances of having a chronically ill child seemed to, for some of the participants, bring the couples closer together such that the husband supported his wife's effort to care for the child and commit to his responsibility as the father.

The stress also affected how the family as a whole related to one another. While the participants indicated that, in some circumstances, the stress actually proved beneficial in terms of bringing the family closer together, for the most part, each participant indicated that the burden of caring for an ill child or family member resulted in more negative stress in the family generally and between spouse specifically. For example, the most commonly experienced form of stress was when they would have to spend time away from their husband and other children while caring for their sick child in the hospital. Increased stress resulting from isolation and loneliness was a common response. 


\section{Social Life:}

Just as the physical, mental, and emotional aspects of the caregivers' lives are compromised, so, too, is their social life. The social life of the caregivers, who don't receive support from their family, usually is non-existent. Given the exhaustive nature of their caregiving duties, in addition to their established house duty expectations, the caregivers did not have time to enjoy their life, go out and create, or maintain relationships with others. And though having such a social life would likely be beneficial to the caregivers because it would potentially offer some form of social support, most of the time the caregivers did not pursue these activities. The women reported that this was because if they found themselves with any free time, their desire to sleep or engage in traditional household duties, such as taking care of their other healthy children, was more important.

\section{Burden of Caregiving and Coping:}

The stress, worries, and burden of female caregivers appeared to be something that each processed differently and independent of what sort of support is available. How the caregivers each processed this trio of factors seemed to be more a function of their separate capacity to manage their own morale. Accordingly, some of the caregivers placed more stress upon themselves because failure to perform well might be a reflection upon them as poor mothers. Other caregivers seemed to feel the pressure to perform because of the cultural pressures to behave according to what society has dictated. For example, one respondent said, "my husband is on one side and I am in the other regarding 
the time I spend caring for our ill child. My daughter, who is healthy, is still young, and I did not take good care of her or feed her. Because my daughter did not accept the new situation well, we took her to my mom who now looks after her". What this evidenced is that the mother's concern for her sick child is not just restricted why he is in the hospital, but also becomes the focus of her attention when he is at home. Added to this strain, the mother is also preoccupied with her other responsibility as a wife and mother to her husband and other children. She feels that this is her job and yet she feels she is neglecting her family which compounds the stress she is already experiencing. All caregivers experienced some form of common physical malady due to the physical demands of being a caregiver, though they presented differently. However, on the spectrum of stress, worries and burden, each participant said that when it came down to isolating the most deleterious aspect of being a caregiver it was the mental fatigue associated with other mental symptoms such as acute anxiety, endless ruminating about the same thing over and over, insomnia, forgetfulness and prolonged irritation with just about everything and anything. The only participants who seemed capable of dealing with this mental state better than the others were those who either had accepted early on the nature of their child's disease as something out of their control (predestination) or those whose child's illness was not as severe as the children of the other participants.

\section{Future Outlook}

Earlier the concept of predestination was discussed with respect to how it provides the caregiver with a way to cope with her child's ill-health. For all the 
participants interviewed, accepting the situation of a sick child and their immediate role as caregiver to comfort and care for their child is the one thing that most of the participants depend on. Some participants seemed better able to cope and adjust to their situation because of its immediate onset at birth. Hence, to them it was the only life that they had known.

All of the participants, at one point or another, harbored bad feelings either towards their situation or the illness that afflicted their child. Yet, when it comes to coping with their circumstances, most of the participants exhibited an attitude of believing in God and accepting that what is happening to them is the will of God (again, the theme of predestination). For example, for some of the caregivers reported that reading the Quran, praying and seeking to better understand God's will is what enabled them to cope daily. On the other hand, others found greater solace in having someone to talk to, especially their own mothers, and they reflected on how that person had been a role model throughout life. Still, other caregivers sought to gain daily strength and reassurance by journaling, reading about optimistic people or following these same people via social media such as twitter, Instagram, snapchat or Facebook. Finally, there are some participants who, through sheer acts of will, demanded that they be strong both for themselves and for their sick child. For these caregivers their thinking was, "if I show resolve in being stronger in the face of this disease, my child will both be assured that they will get well and that they, too, will act strong and brave as well." 
For other caregivers, their ability to cope and adjust appeared to be a function of the frequency with which they had to visit the hospital for the child's check-ups. These mothers seemed to adopt a more empathetic approach that involved viewing the illness through the eyes of their child and understanding how their lives would likely be limited given their diagnosis. These women applied this logic to themselves and imparted to their families that their own problems paled in comparison to the health issues the sick child lives with constantly. Some of the participants have even gone as far as to try to minimize the number of hospital visits by purchasing some of the rather expensive equipment, such as a ventilator, and having it in their own homes. Not only does this reduce the frequency of going to the hospital, but it also underscores the seriousness of the child's condition to the rest of the family, thereby impressing upon the family that a particular illness doesn't just affect the ill child; it affects the entire family.

\section{Theme 2: Social Support:}

Overall, the level of social support, both formal and informal, is inconsistent across the familial units and bureaucracies that the caregivers need to interact with. Based upon the participants' responses to the interview questions, it seems that a big part of the problem has to do with both the caregivers' families and the various agencies dealing with the caregivers not adequately understanding or making the effort to understand the nature and scope of the caregivers' burden. Responses and observations generally reflect a lack of ability on the part of both families and medical personnel to 
appreciate the extreme demands that are faced by primary caregivers of chronically ill children.

In part, this is a cultural phenomenon. The KSA is a highly gendered culture that clearly defines the roles that Saudi men and women play. In the case of Saudi women, their role is clearly defined as being the overseer of her children's welfare and the primary facilitator ensuring that the household runs smoothly. By contrast, the Saudi man's role is to be the major or sole breadwinner and the leader of the family unit. In the KSA culture, concerns of women, especially related to childcare, have never been paramount. Thus, it is unsurprising that Saudi men are largely uninvolved in the care of children. Because of this, they may not be able to fully comprehend or appreciate the enormous burden and sacrifice their wives are under or making to care for a seriously ill child. For example, one participant explicitly indicated that her husband failed to appreciate the burden she had to endure in caring for their ill child, and never offered to assist in any way. She further communicated that the stress in her life reached a point that it spilled over into their marriage, and they began to have marital issues. In one case, the respondent indicated that the stress in her marriage, due in large part to her husband's unwillingness to help, resulted in more conflict between them. Another participant expressed frustration over expectations that she takes full responsibility for the care of the ill child, while still maintaining her duties as both a wife and the overseer of the household including the cooking and cleaning. However, cases reflecting an extreme lack of support are more the exception than the norm for the participants interviewed. As 
discussed in the following section, female caregivers reported receiving varying degrees of social support, the greatest of which came from their families.

It is worth noting that some interesting observations were made with respect to the caregivers freely expressing their feelings about their circumstances and the pivotal role that having adequate social support would play in making their caregiving burden more tolerable. For example, when the caregivers where asked about whether they could express their feelings related to caring for a chronically ill child in the presence of other people, roughly half of them said no. This is curious given that the function of having social support is to allow a dialog among two people to share what is on each other's minds so as to understand different ways of coping. But, it does seem to support prior studies (Ali et al. 2008; Cohen, Azaiza and Manassa 2013; Azaiza and Cohen 2008; Katooa et al. 2015) that suggest that a desire to communicate strength and avoid any expression of weakness (concordant with women's roles as family overseers) may prevent such women from seeking support.

Nonetheless, when the PI asked the participants whom they discuss their situation with, those who indicated a reluctance to discuss their feelings in the presence of others qualified their answers and said that they felt little reticence in talking with either a friend, a sister or another non-male family member except for their immediate husband. Those caregivers who expressed a willingness to share their feelings with others said they usually talked with their family members, such as a sister, mother, husband, and/or with a close friend. Most of these caregivers indicated a preference for talking with their sister, 
followed by their husband. Surprisingly, discussing their feelings with their own mother was last. Asked to further clarify their reluctance to discuss their caregiving burden with a non-family member, such as coworker and acquaintances, the caregivers indicated that they were simply being conscious of the feelings of their child and that they did not want to solicit any sympathy from others regarding their current stressful situation. In fact, the participants said that "there is no benefit from talking [other than], say, talking to God. It was startling to hear that, for the most part, the participants did not feel that there was any benefit to be derived from talking with those outside of their immediate circle of family and friends about the stresses they feel from their caregiving duties.

Interestingly, the participants did express the view that if they were to talk to others, it was more likely that they would prefer to be the ones imparting advice to other mothers like themselves who were just beginning to experience the burdens of caregiving. In this sense, the participants saw benefit in acting like their own social support system by sharing their knowledge with other caregivers as to the best strategies to cope with the burden of caring for a sick child. Finally, while the mothers expressed little interest in the need for social support for themselves; they did perceive value in social support for their sick children. Earlier it was discussed that for some of the mothers, they found strength in either reading or following optimistic people. Similarly, these mothers felt favorable toward any social support that was directed at their ill children. Their attitude was that any social support that served to boost their children's spirits was beneficial. 


\section{Formal Social Support:}

Formal social support may be thought of as the support that is offered by professionals or public services that are available to the caregiver. The next section describes the needs of caregivers with respect to social support from the bureaucracies and agencies that they may come into contact with during the course of their caregiving duties. Though only a partial representation, what the discussion underscores is that formal social support in the KSA is the most inconsistent and hardest to come by. It has already been discussed that healthcare in the KSA, something that every Saudi citizen is entitled to, is not what one would expect it to be given the enormous wealth and investments of the nation. It was also previously touched upon that the majority of medical professionals are specialists rather than family practitioners. This is attributable to the KSA's approach to medicine which is primarily curative rather than preventative. Moreover, a great majority of the specialists who practice in the KSA are not Saudi nationals, but rather doctors from abroad for whom Arabic is not their native tongue. Additionally, the training of a medical specialist is generally longer and more intensive than that of a general internist or family practitioner. With a greater emphasis as "fixers" of a medical issue than preventers of disease, the specialists within the hospital become less empathetic and exhibit a diminished capacity to relate to patients as people rather than objects that need to be repaired. As Ha et al (2010) point out, "It has been observed that communication skills tend to decline as medical students progress through their medical education, and over time doctors in training tend to lose their focus on holistic 
patient care. Furthermore, the emotional and physical brutality of medical training, particularly during internship and residency, suppresses empathy, substitutes techniques and procedures for talk, and may even result in derision of patients" (2010: 39). Because the participants tended to be seen by either specialists or ER personnel, whose primary function is to triage patients as quickly as possible, they tended to not be on the receiving end of the type of empathetic treatment that they would have ordinarily experienced had they been seen by a family practitioner. Accordingly, the type of formal social support they received was perfunctory at best and completely absent at worst. Participant responses to the question "Describe the type of formal social support you experienced at the hospital" ranged from "the doctor sometimes makes you feel hopeless and didn't care about us as caregivers. In fact, one of the nurses told my mom that her son is going to die" (Participant \#15). Another respondent reported that doctors told her that it was their job, not hers, to diagnose what was wrong with her daughter even though all the participant was looking for was some explanation as to what was wrong with her daughter (Participant \#20). To be sure, it is not only the hospitals that came up short when it came to extending a modicum of formal social support.

The governmental agencies that worked with some of the participants whose children suffered from kidney issues were especially inept when it came to extending any sort of formal social support to assist the caregivers. In one instance, a participant's son was receiving a government stipend during the period he was waiting for a kidney transplant. Once the kidney transplant occurred, this participant's son stopped receiving 
any government assistance. However, when the transplanted kidney started to be rejected and ultimately failed, the government did not resume any government support for the child. In sum, no evidence of formal social support was evidenced in the responses of participants. The participants commonly expressed a lack of perceived support or empathy from medical staff, none reported that they received information or resources from medical staff or other agencies.

\section{Informal Social Support:}

In contrast to formal support, informal support is the support that caregivers may receive from family members, friends, or neighbors. For most of the participants the primary source of informal social support was the immediate family who were most likely to provide emotional support. Within the immediate family, caregivers reported that the primary source of the social support was their husband. Beyond husbands, the most likely family member to offer social support to respondents was a sister. Among female caregivers who did not have any female siblings, some support came from brothers, but this was not common as the male side of the sibling relationship is not as emotionally demonstrative as the female side. Occasionally, respondents reported support from a mother. The participants did not indicate that they sought out any form of social support from their in-laws.

Outside the immediate family, friends ranked as high as sisters in providing a source of social support and in the absence of sisters, the participant's friends were preferable over the participant's brothers. Interestingly, the participants did mention that 
for those of them who had both sisters and brothers, though they would talk more often with their sisters, their brothers were more proactive in reaching out to the sister to see how they were doing.

Social media was revealed to be a valuable source of social support. Participants utilized social media for informational support (i.e. to express opinions and seek guidance) as well as emotional support, i.e. to develop new relationships that proved crucial in allowing the participants to share their experiences with other caregivers who were just starting down the path of caring for a chronically ill child. Heavy usage of Whatsapp as a means of keeping in contact with other caregivers that the participants met at the hospital was reported. However, this type of support was used informally which means it was created by the caregivers themselves which makes it harder for other participants to join these groups. Additionally, both Twitter and Instagram were reported as valuable to the caregivers to make connections with other caregivers in order to share their experiences, exchange contact information and keep abreast of developments and methods of making the caregiving experience less burdensome.

Social Support - Reliance Upon and Utility Of:

Based upon all of the participants' answers, it is clear that informal social support is preferable for a number of reasons. First of all, it is both consistent and accessible. By the very nature that the source of the social support is familial, this resonates deeply with each of the caregivers interviewed. Moreover, there is a vested interest in the welfare of each caregiver from both her immediate family and her circle of friends. Unlike the 
hospitals where the caregivers take their ill child for treatment and are dealt with by basically disinterested third parties, the families of the caregivers have an unbreakable bond tied by both heritage and cultural customs such as a shared belief in Allah.

Even though, as earlier discussed, the family unit within the KSA is becoming more nuclear in makeup, the basic bloodline of ancestry is what each caregiver can count on, for it means that even when things are at their worst their immediate and extended families will respond to any request for help and offer their best. In terms of the specific source of informal social support that caregivers said they could unequivocally count on, husbands emerged as the primary response. This was based on feelings that husbands understood their feelings on a different level than that of the family in which they were reared. Interestingly enough, some of the participants indicated that in cases in which their husband was unwilling to be a partner in helping the caregiver deal with her burden, it was not her that would be affected as much as the family. Essentially, the caregivers were willing to carry on with what they saw as an inviolable obligation irrespective of whether or not the husband was willing to assist her. And for some of the participants, a husband unwilling to assist them was a husband they were not willing to stay with.

Influence of Cultural Practices:

The cultural practices that tend to occur have already been touched upon, specifically a belief in predestination or acceptance of the circumstances as being the will of God. Additionally, reliance upon their belief in Allah served as a source of strength to deal with the burden of caring for an ill child. It is also this belief, some of the 
participants said, that allowed them to feel as though they did not need to seek social support beyond that which was provided by their faith. An additional cultural practice that was not part of the interview questions but which the PI introduced via further probing was related to an unshakeable faith in Allah and the cultural dictum of what a Saudi woman is supposed to do and how she is supposed to behave. Specifically, respondents were asked if this served to provide order and structure for the caregivers when they seemed to feel like their world was spinning out of control with worry and anxiety about their ill child. For some of the participants, they acknowledged that this was beneficial for they knew that if they had to do something related to taking care of the other members of the family, it served as a brief diversion from something out of their control. In effect, when the participants knew that they could engage in an activity where they could control the beginning, the middle and the end, they felt like some order had been restored in their lives. And when their efforts were greeted with appreciation from the other family members, it enabled them to put things in perspective with regards to their current circumstances. Earlier responses suggested an intense desire to successfully fulfill obligations as a mother and wife, and this may further explain this sentiment.

Caregiver's Needs:

Importantly, what the caregivers explicitly communicated as needing in order to be more efficient caregivers was information and accessibility to medical staff. The participants unanimously said that having more time with the medical staff to discuss their child's condition and answer the mother's questions about treatment, as well as what 
they as caregivers could do better to make their children comfortable is something that was stressed as a pressing need. This has important implications for practice as it suggests a relatively simple mechanism through which formal support might be offered to caregivers. This particular need was more paramount for the caregivers who had to travel a considerable distance. In those instances, the caregivers cited both the lack of attention from the doctor and a general disregard for how difficult a job the mothers had in their role as caregiver. One participant specifically mentioned time constraints that may prevent adequate care and attention. She indicated that her doctor, after apologizing, told her that she didn't have any more time to spend discussing the child's case as she had more patients to see. Time pressures and institutional demands for efficiency have been associated with poorer care in other countries and may be a consequence of a medical establishment that approaches medicine from a curative, as opposed to a preventative, standpoint.

Several studies have highlighted the indifference exhibited by medical professionals. In a study conducted by Alzayer et al (2019) the team pointed out that, "patients assigned the lowest scores to the following items: "the doctor asks about what is happening in my daily life" and "the doctor seems concerned about me and my family." Another study reported similar findings as patients reported very low scores on items such as: "the doctor asks what is happening in my daily life" and "the doctor can view things from my perspective" (Borracci et al. 2019: 203-204). The participants of the 
present study related similar concerns and expressed a desire for the medical community to help them be better caregivers.

More importantly, however, and directly relevant to the research questions raised is that in instances where the caregivers are interacting with the medical community and asking for both their attention and empathy and finding the doctors less than generous with their time, what they are experiencing is a direct denial of social support. In the absence of having family and friends lend a supportive hand to assist in easing the caregiver's burden, the next and best opportunity is from the medical community. Consistent with prior studies that suggest an inability to offer empathy on the part of medical professionals, this study reveals similar experiences that suggest acting as a social support mechanism is not what the medical and hospital staff have either been trained to do or are interested in getting involved with.

Because the healthcare system in the KSA takes a curative, as opposed to a preventative, approach to medicine, the participant group interviewed for this study offered up a number of pressing needs that if met would enable them to not only be better caregivers, but also would prove invaluable in easing the significant burden they have to bear as the child's caregiver. The following lists some of the needs the caregivers felt that if met would help them immensely:

- "I would like to understand if there is any formal guidance from the hospital about my daughter's situation and how I can best use this information" - Participant \#3.

-I would like for the hospital to make a counseling office available in order to answer any questions I may have as well as questions that other parents may have" - Participant \#6 
- "I want the doctors and medical staff to tell me if there is a treatment for my daughter and to be honest with me about my daughter's condition and long-term prognosis. She almost died in front of me, and I feel I am not getting answers to all my questions." Participant \#14

- "I need to know why certain symptoms are occurring with my ill child such as his continuous diarrhea. What is happening here and is this common?" - Participant 29

- "As caregivers, we need some official channel either on Social Media or tied into the hospital in some way so that other caregivers can get the support they need and answers to questions both they and their kids have about their condition." - Participant \#33

- "As mothers, we caregivers really suffer. I wish there could be a workshop sponsored by the hospital that could teach us how to deal with our kids during an emergency. It's important for us to be knowledgeable of what to do especially during an emergency when we cannot get to the hospital easily." - Participant \#28

- "The doctors need to show some compassion when they are delivering bad news regarding my child's condition." - Participant \#1

- "We need some real help in being able to not only navigate the medical system, but also the medical problem. We need someone who understands us and the specific condition of our child. We don't feel that the hospital and the staff are doing enough to be attentive to both our needs as parents and to the special needs of our child. They have already shown negligence in not properly entering medical notes in his chart such that they don't even know which doctor is supposed to be caring for our son. They even forgot some of his meals." - Participant \#15

-"There should be some type of support system within the hospital here. A formal support system that could prepare a group support system both inside and outside the hospital. This would be especially helpful for those mothers who wind up staying at the hospital, with their child, sometimes for more than one moth." - Participant \#27

- "The hospital should offer some educational classes in order to prepare the mothers on how to accept and deal with the new situation or at least a counselor to advise the caregivers about how to manage their lives and deal with their child and his or her new illness. After all, hospitals already provide this sort of education for when mothers have a newborn child." - Participant \#18

Conclusion:

In conclusion, the female caregivers interviewed voiced that between informal and formal social support, it was the informal or familial social support that they could 
count on the most. Though the sample of caregivers interviewed for this study is but a miniscule representation of the larger community of female caregivers in the KSA, it is highly probable that the situation for other female caregivers in other major cities in the KSA is similar It is evident from the interviews and additional research that female caregivers in the KSA experience intense caregiving burdens and subsequent physical or mental health issues. Indeed, their quality of life is compromised in a number of ways. Arguably, those who don't receive support from either their family or relatives are at greater risk in terms of their overall health. This is the preventative end of healthcare that is not prevalent in the KSA and one pressing reason that the approach to healthcare in Saudi Arabia needs to change.

The foregoing suggests opportunities for improvement. When the participants were asked for their suggestions of what can be done to improve on the caregivers' QoL particularly as it pertained to medical aspects of what they do, the following recommendations were offered:

1. The doctors and/or other medical professionals should actively encourage the presence of the husband or any family member to understand the situation that the patient and primary caregiver are put in and collaborate towards ensuring that the health of both caregiver and patient are never compromised due to a break down in the continuity of care.

2. The doctors and/or other medical professionals, as well as the general medical community at large, should actively encourage Education classes and workshops for the caregivers to teach them how to deal with their kids in normal and emergency situations. 3. The doctors and/or other medical professionals, as well as the general medical community at large, should actively work with the Ministry of Health to improve the quality of the primary health clinics and clinical staff so that the professionals who man these clinics are available to answer the caregivers' concerns every day and without 
delay. Moreover, the caregivers need to be given greater access to the specialists in charge of treating their children while also not being restricted as to how much time they need to fully get the answers they need from the physicians in charge.

4. The medical community needs to ensure that caregivers are provided either a dedicated counselor or access to a group of dedicated counselors who can manage the caregiver's life and help them with the problems they may face in general. In other words, a Caregiver Ombudsperson. 


\section{CHAPTER VI: CONCLUSION}

A large body of research has documented the increased physical and emotional burdens associated with caregiving as well as the beneficial role of social support in offsetting related strains. However, a very limited amount of research has examined the experience of female caregivers in the KSA, and with the exception of one study by Katooa et al. (2015), none have considered the role of social support in improving the lives of Saudi females. To address this gap, this dissertation addressed the following two research questions: (1) What is the experience of female caregivers with chronically ill children in KSA, and (2) What is the nature and availability of social support among these women?

As was mentioned previously, little is known about the experience of female caregivers in the KSA. Findings from this study suggest that these caregivers spend an extraordinary amount of time engaged in caregiving duties. In fact, $54.3 \%$ of caregivers spent more than 16 hours caring for patients; $14.3 \%$ spent between 8 and16 hours a day; the remaining $31.4 \%$ spent 4 or fewer hours per day engaged in caregiving activities. Importantly, variations in time spent in caregiving had much to do with the relationship of the female to the chronically ill child. Accordingly, the vast majority of women who reported high amounts of caregiving time were mothers, while those who spent less time caregiving had various relationships to the children. For example, the women who reported less than 4 hours were often aunts, a grandmother or a sister. Some women reported that they had access to assistance with housework or childcare (via privately 
employed individuals); however, this was highly variable on the basis of income and education. Approximately $20 \%$ women utilized a paid worker to assist with household tasks.

Women who were employed reported that they spent less time with caregiving (as evidenced by the fact that most reported fewer hours than those who were not employed). However, though recent trends in the KSA suggest increased women's labor force participation (The World Bank 2020; Naseem \& Dhruva 2018), most women who participated in this research were unemployed and primarily engaged in the household care. Notably, several women reported that they gave up their careers or employment in order to take over the care of chronically ill children. Some indicated regret over the loss of their goals but accepted the necessity of the care work and their position as primary caregiver. These findings seem to suggest that despite increased female labor force participation and education, gender and family norms remain firmly entrenched.

Prior research has suggested that quality of life is negatively impacted by caregiving (Al-Akour and Khader 2008). An examination of the caregivers' QoL found similar results, most of which indicated that the burden of caregiving had a deleterious effect on their emotional and physical well-being. All of the women interviewed suggested that they suffered from negative mental or physical outcomes including exhaustion, depression, and anxiety. Approximately one third of the respondents indicated that their overall health had deteriorated over the past year due to the stress of their caregiving duties. Moreover, when the participants were asked what illnesses they 
had, about $60 \%$ of the caregivers indicate that they have one or more diseases such as diabetes, hypertension, heart disease, high cholesterol, anxiety, and depression.

The physical impact of caregiving was not the only negative consequence felt by the respondents. Many reported a profound sense of isolation that was overwhelming and, in many cases, resulted in depression. Participants also commonly mentioned loss of sleep or appetite due to stress. However, most women communicated an unwillingness to mention these concerns to others. For example, several women said that they were conscious of the feelings of their child, and, hence, reluctant to discuss their current circumstances with anyone else. They did not want to solicit any sympathy from others regarding their current stressful situation. In fact, the participants said that, "there is no benefit from talking [to others] other than talking to God". Those caregivers who expressed a willingness to share their feelings indicates that they preferred talking with a sister, followed by a preference for husbands. Interestingly, mothers were the last family members they expressed an interest in sharing feelings with. Additionally, the participants expressed the view that if they were to talk to others, it was more likely that they would prefer to be the ones imparting advice to other mothers like themselves who were just beginning to experience the burdens of caregiving. These findings seem to echo those observed in earlier studies (e.g.Goldblat, Cohen, Azaiza \& Manassa 2013; Azaiza \& Cohen 2008) that suggest that Arab women desire to be perceived as strong heads of household and want to avoid the perception that they have somehow failed in 
their mothering or household duties. Again, such findings seem to suggest an internalization of gender roles.

The caregiving burden often resulted in changes to the family's sense of what is normal, whether it's assigned roles or relationships. For some, the stress actually proved beneficial in terms of bringing the family closer together. In these cases, the women reported that caring for a chronically ill child offered them the opportunity to increase equality in their relationships and husbands were willing to step in and assist with duties. In this way, chronic illness may allow husbands to let go of cultural norms and be more supportive. But, for the most part participants indicated that the burden of caring for an ill child or family member resulted in more negative stress in the family generally and between individual members specifically. In a few cases, respondents reported that the stress resulted in divorce or separation. It is possible that the presence of a chronically ill child leads some women to reject cultural norms as they exert some autonomy in this context. In others, the women generally reported feelings of despair over their perceived lack of support from family members. The women generally did not feel that they were able to express their concerns or that it would be appropriate to discuss such feelings. Each caregiver experienced the burden of caring for their ill child in different ways but that did not lessen the impact the burden had on their lives.

The KSA is a highly religious country with approximately $85-90 \%$ of residents reporting Muslim as their religion. In fact, non-Muslims are not allowed to have Saudi 
citizenship (CIA 2020). Herein, all the respondents were highly religious ${ }^{5}$. The ability of the caregivers to cope with their situation was not uniform except for a reliance upon their faith which was referred to often as a coping mechanism. A majority of the caregivers sought comfort and the ability to cope with their child's illness by accepting their circumstances as the will of Allah. This "predestinational thinking" seemed to allow the caregivers to distance themselves from somehow being responsible for their circumstances and that of their chronically ill child. But this thinking definitely did not remove either their concern or dedication to putting the health of the child as a priority in their lives. Religion has been shown to have a beneficial impact on health in other countries, and scholars have argued that religious individuals exhibit greater coping skills and have access to enhanced social support, which likely explains their improved health outcomes (Ellison and Levin 1998). It is unknown whether the reliance on Allah has a similar beneficial impact in this context or the extent to which women may have access to religious resources or support systems, but this represents an important area for additional research and investigation.

As was described earlier, a large body of research has documented the beneficial impacts of social support on emotional and physical well-being (Henderson and

\footnotetext{
${ }^{5}$ By "highly religious" this is to indicate a strong faith in Allah as evidenced by adherence to Islamic practices mandating prayer 5 times daily (Salat al-fajr: dawn, before sunrise, Salat al-zuhr: midday, after the sun passes its highest, Salat al-'asr: the late part of the afternoon, Salat al-maghrib: just after sunset, and Salat al-isha: between sunset and midnight) and daily reading of the Quaran, as well as providing religious instruction to all children in the familial setting.
} 
Vandanberg (1992); Trivette \& Dunst 1992; Weiss 2002). These studies have identified various forms of support including formal and informal as well as informational, emotional, and instrumental. Findings from this study suggest that women perceive and seek out these various forms of social support in different ways. Overall, none of the women perceived that there was any degree of formal social support available to them. Women expressed a clear desire for some informational support, i.e. formal guidance and instruction on how to care for a sick child and where to go for additional resources, from medical staff. Additionally, with a greater emphasis as "fixers" of a medical issue than preventers of disease, the specialists within the hospital were uniformly viewed by the caregivers as less empathetic and exhibited a diminished capacity to relate to them and their ill children as people rather than objects that need to be repaired. In many cases, the women reported that experiences with medical staff further intensified their strain. It is possible that reliance on external labor in the KSA has intensified this issue given that it may lead to cultural gaps in communication and poorer quality of care. These findings are important given the KSA's effort to improve its healthcare system and offer possible insights into needed improvements.

With respect to informal social support, this was something that the caregivers seemed to be able to access with little or no difficulty. In fact, the women reported receiving emotional support from husbands and sisters; and in terms of order, they indicated clear preferences for husbands followed by sisters. Nearly all rejected the notion of seeking support from mothers and in-laws. This study sheds light on what 
social support means to female caregivers in the KSA and generally seem to suggest that women consider informal social support to be primarily emotional in nature. Interestingly, instrumental support was not among the forms the women perceived as available, nor did they express a desire for greater support of this nature.

Prior studies have further indicated that social support has been shown to buffer the harmful effects of stress (Cassel, 1976; Cobb, 1976; Henderson, Byrne, DuncanJones, et al, 1980; Kaplan, Cassel, \& Gore, 1977) To this end, Cassel addresses the term social support in terms of its ability to provide "protective factors buffering or cushioning the individual from the physiologic or psychological consequences of exposure to the stressor situation" (1976: 113). Cobb (1974, 1976). Consistent with stress-buffering theory, the findings herein suggest that Saudi females have identified a number of positive coping mechanisms. Indeed, the caregivers reported feeling they received quite a bit of emotional support from their husbands, female friends, their sisters, and friends that they cultivated through social media. Moreover, social media emerged as an important source of both emotional and informational support. This method of connection appeared to offer a space for the women to freely express their concerns, share their stories, gather information on coping with illness and caring, and connect with others. As such, it represents an important avenue for further research among Saudi women.

Overall, the most pressing needs sought by the caregivers was an overhaul to the manner in which the medical community dealt with them and their chronically ill 
children. The caregivers desperately wanted more specific guidance from the professional medical community as to how to properly care for their chronically ill children. They were looking for a more hands on approach from the doctors and nurses in helping them deal not only with the care of their chronically ill children, but also the stress that the caregivers were under which tended to manifest itself in the caregiver's own health being compromised.

Collectively, the findings in this study demonstrate that the impact and value of social support upon the lives of female caregivers in the KSA cannot be underestimated. Easily and widely made accessible, the benefits that would accrue to the caregivers in this study is self-evident as indicated by how important even the briefest of respites would be form the daily grind of caring for a chronically ill child. While the most primary and beneficial of the social support systems available to the participants in this study appears to resides within families, this study yields important insights into additional contexts in which social support might be formalized and improved. Namely, hospitals, the medical care community at large and the governmental agencies, such as the $\mathrm{MOH}$, have an opportunity to make both a quantitative and qualitative difference in the quality of lives for Saudi citizens with some investments in training and additional investigation into mechanisms that might provide more formal social support for caregivers.

Limitations

While this study did provide further evidence to support the conclusions of other researchers as to the benefit of social support upon the lives of people tasked with caring 
for ill family members, it is not without some limitations that would make it an even more robust study. One significant limitation of the present study is that it is not longitudinal in scope. What has been presented here is basically a balance sheet of where both informal and formal social support stands in present day Saudi Arabia. In essence, it's a snapshot and nothing more. However, placed within a continuum of studies that chart the evolution of the KSA's medical system, along with more attention being paid to the welfare of formal caregivers, it suggests the need for more investments and attention to social support, especially of the formal kind, by the bureaucracies within the KSA such as the $\mathrm{MOH}$.

Another significant limitation was the sample size. Notwithstanding the fact that 35 participants represents the standard acceptable minimum for this research study, it is axiomatic that there are substantially more than 35 female caregivers in the KSA who are undergoing the shared experiences of the caregivers documented in this study. Nonetheless, the female caregivers documented herein likely expressed shared experiences with other female caregivers whose lives are being unnecessarily burdened due to issues related to gaps in care as well as by cultural practices that allow Saudi men to avoid and encourage men to avoid household duties including childcare. In addition, the PI was restricted to a specific time frame within which to conduct her study (the 3 summer months of 2018), which limited the number of participants that could be interviewed. For the purposes of generalizability, a much larger universe of participants would have been preferable. The reason for this is that by canvassing a larger sample 
size of participants the margin of error is reduced. In 2019 for example, women made up 42.60 percent of the population of Saudi Arabia (14.54 million out of a population of

\subsection{4 million) (https://www.globalmediainsight.com/blog/saudi-arabia-population-}

statistics/). Of this number, approximately 9.68 million, or 67 percent, were between the ages of 14 and 64, which closely approximates the ages of the participants in the study. With the sample size of this study being 35 individuals, it is obvious that less than 36 one hundredths of one percent of the Saudi female population that might possibly be undertaking caregiving activities was interviewed. To be sure, it is highly unlikely that almost ten million Saudi women are caring for an ill child or other family member. However, it is conceivable that there are many more female caregivers in the KSA who are enduring the same experiences as the 35 individuals interviewed for this study. Furthermore, in-depth interviews allow for a much richer level of detail with respect to respondents' experiences, and given the lack of information available on these women's lives, the in-depth nature of this investigation lends additional strength to this study.

The singular strength of this study is that it was done at all. As has been evident from the literature reviewed, the plight of female caregivers in the KSA has not garnered much ink within the academic community. In fact, Aldosari (2017) said this, which was previously mentioned,

"Saudi Arabia has a unique culture in which gender roles and expectations are based on a specific interpretation of Islamic sharia. These roles are strictly enforced through legal and societal measures. Consequently, women may find 
health services inaccessible, unavailable, or conditioned on certain cultural justifications or gender norms. Limitations on women's autonomy, such as those imposed by the male guardianship system, women's driving ban, gender segregation, and religious norms, influence access, quality, and outcomes of health care for women in Saudi Arabia." (2017, p. 6)

This study's strength is that it becomes a reference point for other studies to build upon and further investigate what is, can and must be done to alleviate the situations that female caregivers in the KSA find themselves in.

Future Research

As was mentioned above, this study yielded a number of insights into areas of needed research. For example, findings related to the importance of religion taken together with prior work documenting the beneficial role of religion on health suggest this is a potentially fruitful area for additional investigation. Similarly, more work is needed to determine the extent to which the various coping mechanisms observed in these women have resulted in beneficial health impacts. Finally, intense changes to social and economic structures with resultant changes to female labor force participation and education will likely continue to influence gender and family roles. Ongoing investigation is needed to examine these issues.

The hope of this author is that this study breaks new ground, sheds new light and starts a much needed and vastly overdue dialog among the stakeholders who can and must make a difference in the lives of not only the chronically ill Saudi children, whose 
numbers continue to grow, but also the countless caregivers who operate in the shadows, doing what must be done, often alone, in the hopes of restoring their children to full health. 


\section{REFERENCES}

Aboul-Enein, F.H. (2002) Personal contemporary observations of nursing care in Saudi Arabia. International Journal of Nursing Practice 2002; 8:228-230

Al-Akour, N. and Khader, Y. S. (2008). Having a child with asthma-Quality of life for Jordanian parents. International Journal of Nursing Practice, 15: 574-579. doi:10.1111/j.1440-172X.2009.01796.X

Aldosari, H. (2017). The effect of gender norms on women's health in Saudi Arabia. The Arab Gulf States Institute in Washington, http://www.agsiw.org/effect-gender$\underline{\text { norms-womens-health-saudi-arabia/ (2017, accessed } 18 \text { February 2020). Google }}$ $\underline{\text { Scholar }}$

Al-Faris E, Khoja T, Falouda M, Saeed A. (1996). Patient's satisfaction with accessibility and services offered in Riyadh health centers. Saudi Med J. 1996;17(1):11-7

Al-Ghanim, Kaltham. (2013). The Hierarchy of Authority Based on Kinship, Age, and Gender in the Extended Family in the Arab Gulf States.

Al-Hanawi, M.K., Alsharqi, O., Almazrou S., Vaidya, K. (2018). Healthcare finance in the Kingdom of Saudi Arabia: a qualitative study of householders' attitudes. Appl Health Econ Health Policy. 2018;16:55-64.

Al-Hanawi M.K., Khan, S.A., Al-Borie, H.M. (2019). Healthcare human resource development in Saudi Arabia: emerging challenges and opportunities - a critical review. Public Health Rev. 2019;40:1. 
Al-Hanawi, M. K., \& Qattan, A. M. (2019). An Analysis of Public-Private Partnerships and Sustainable Health Care Provision in the Kingdom of Saudi Arabia. Health services insights, 12, 1178632919859008. doi:10.1177/1178632919859008

Alharbi M. F. (2018). An analysis of the Saudi health-care system's readiness to change in the context of the Saudi National Health-care Plan in Vision 2030. International journal of health sciences, 12(3), 83-87.

Ali, M.E.S., Mahmoud, M.E.A. (1993). A study of patient satisfaction with primary health care services in Saudi Arabia. J Community Health. 1993; 18(1):49-54

Ali, S. R., Mahmood, A., Moel, J., Hudson, C. \& Leathers, L. (2008). A qualitative investigation of Muslim and Christian women's views of religion and feminism in their lives. Cultural Diversity and Ethnic Minority Psychology, 14(1), 38.

Al-Khashan, H., Mishriky, A., Selim, M., Sheikh, A., Binsaeed, A. (2011). Home caregivers' satisfaction with the services provided by Riyadh Military Hospital's home support program. Annals of Saudi medicine. 31. 591-7. 10.4103/02564947.87095 .

Al-Khateeb, S. (1998). Women, Family and the Discovery of Oil in Saudi Arabia. Marriage \& Family Review. 27. 167-189. 10.1300/J002v27n01_11.

Alkohaiz, M. A. (2018). "Educational, financial, and social needs of families of children with multiple disabilities in Saudi Arabia." (2018)

Almalki, M., Fitzgerald, G., Clark, M. (2011). Health care system in Saudi Arabia: An overview. Eastern Mediterranean health journal = La revue de santé de la 
Méditerranée orientale = al-Majallah al-ṣiḥhịiyah li-sharq al-mutawassiṭ. 17. 78493. 10.2147/NDT.S48782.

Alosaimi, Maha. (2017). Sickle cell disease in Saudi Arabia: A challenge or not. Journal of Epidemiology and Global Health. 7. 10.1016/j.jegh.2016.12.006.

Al-Qatari, G., Haran, D. (1999). Determinants of users' satisfaction with primary health care settings and services in Saudi Arabia. Int J Qual Health Care. 1999; 11(6):523-31

Al-Qurashi, M. M., El-Mouzan, M. I., Al-Herbish, A. S., Al-Salloum, A. A. \& Al-Omar, A. A. (2009). Age related reference ranges of heart rate for Saudi children and adolescents. Saudi Medical Journal, 30(7), 926-931.

Alrashed, A. M. (2017). Illustration of informal caregiving within Saudi society: demography, scope of care and enabling arrangements. Scandinavian Journal of Caring Sciences, 31(2), 263-272. https://doi.org.liboff.ohsu.edu/10.1111/scs.12339

Al-Sakkak, M.A., Al-Nowaiser, N.A., Al-Khashan, H.I., Al-Abdrabulnabi, A.A., Jaber, R.M. (2008). Patient satisfaction with primary health care services in Riyadh. Saud. Med J. 2008; 29(3):432-6

Al-Saleh, S. A. (2012). Gender inequality in Saudi Arabia: Myth and reality. International Proceedings of Economics Development \& Research, 39. 
Al-Shahri,M. (2002). Culturally Sensitives Caring for Saudi Patients. Journal of transcultural nursing : official journal of the Transcultural Nursing Society / Transcultural Nursing Society. 13. 133-8. 10.1177/104365960201300206

Alshammari, B., Noble, H., McAneney, H. et al. (2019). An exploration of symptom burden and its management, in Saudi Arabian patients receiving hemodialysis, and their caregivers: a mixed methods study protocol. BMC Nephrol 20, 250 (2019). https://doi.org/10.1186/s12882-019-1424-9

AL-Sharfi, M. A. (2017). "The Effect of Family Structure on Adolescents in Saudi Arabia: A comparison Between Adolescents from Monogamous and Polygamous Families". Doctoral Theis, University of Lincoln

Alsumaih, I.S., Aldhuwayhi,F.A. (2015). Characteristics of Medical Services in the US Versus Saudi Arabia. Science Journal of Public Health. Vol. 3, No. 4, 2015, pp. 588-591. doi: 10.11648/j.sjph.20150304.29

Al-Turki, Y. A. (2000). Overview of chronic diseases in the Kingdom of Saudi Arabia. Saudi Medical Journal, 21(5), 499-500.

Amendola, Fernanda, Oliveira, Maria Amelia de Campos, \& Alvarenga, Marcia Regina Martins. (2010). Influence of social support on the quality of life of family caregivers while caring for people with dependence. Journal of the School of Nursing of USP , 45 (4), 884-889. https://dx.doi.org/10.1590/S0080$\underline{62342011000400013}$ 
Aneshensel, C. S., \& Stone, J. D. (1982). Stress and depression: A test of the buffering model of social support. Archives of General Psychiatry, 39, 1392-1396.

Antonucci T.C. (1985). Social Support: Theoretical Advances, Recent Findings and Pressing Issues. In: Sarason I.G., Sarason B.R. (eds) Social Support: Theory, Research and Applications. NATO ASI Series (D: Behavioural and Social Sciences), vol 24. Springer, Dordrecht

Antonucci, T. C., \& Israel, B. A. (1986). Veridicality of social support: A comparison of principal and network members' responses. Journal of Consulting and Clinical Psychology, 54(4), 432-437.

Azaiza, F., \& Cohen, M. (2008). Between traditional and modern perceptions of breast and cervical cancer screenings: a qualitative study of Arab women in Israel. Psycho-oncology, 17(1), 34-41. https://doi.org/10.1002/pon.1180

Baanders, A. N., \& Heijmans, M. J. W. M. (2007). The impact of chronic diseases: The partner's perspective. Family \& Community Health: The Journal of Health Promotion \& Maintenance, 30(4), 305-317. http://dx.doi.org/10.1097/01.FCH.0000290543.48576.cf

Baghdadi, Z. D. (2011). Managing dental caries in children in Saudi Arabia. International Dental Journal, 61(2), 101-108.

Bahry, L. (1982). The New Saudi Woman: Modernizing in an Islamic Framework. Middle East Journal, 36(4), 502-515. Retrieved February 17, 2020, from www.jstor.org/stable/4326467 
Barlow, J. H., \& Ellard, D. R. (2006). The psychosocial well-being of children with chronic disease, their parents and siblings: an overview of the research evidence base. Child: care, health and development, 32(1), 19-31.

https://doi.org/10.1111/j.1365-2214.2006.00591.x

Baron, R.M., \& Kenny, D.A. (1986). The moderator-mediator variable distinction in social psychological research: conceptual, strategic, and statistical considerations. Journal of personality and social psychology, 51 6, 1173-82.

Barrera, M. (1986). Distinctions between social support concepts, measures, and models. American Journal of Community Psychology, 14(4), 413-445.

Berkman, L. (1984). Assessing the Physical Health Effects of Social Networks and Social Support., Annual Review of Public Health P 413-432, V 5, R10.1146/annurev.pu.05.050184.002213,https://www.annualreviews.org/doi/abs/ 10.1146/annurev.pu.05.050184.002213K

Berkman, L., Sekher. T., Capistrant, B., Zheng, Y. (2012). Social Networks, Family, and Care Giving Among Older Adults in India., National Research Council. (2012). Aging in Asia: Findings from New and Emerging Data Initiatives. J.P. Smith and M. Majmundar, Eds. Panel on Policy Research and Data Needs to Meet the Challenge of Aging in Asia. Committee on Population, Division of Behavioral and Social Sciences and Education. Washington, DC: The National Academies Press. 
Bellin, M. H., \& Kovacs, P. J. (2006). Fostering resilience in siblings of youths with a chronic health condition: A review of the literature. Health \& Social Work, 31(3), 209-216

(24) (PDF) From Risk to Resilience. Available from:

https://www.researchgate.net/publication/282660274_From_Risk_to_Resilience [accessed Jul 06 2020].

Brooks, K. P., Gruenewald, T., Karlamangla, A., Hu, P., Koretz, B., \& Seeman, T. E. (2014). Social relationships and allostatic load in the MIDUS study. Health psychology : official journal of the Division of Health Psychology, American Psychological Association, 33(11), 1373-1381. doi:10.1037/a0034528

Brown, G. (2005). International nursing department: An up close and personal look at Saudi Arabia (Jeddah and Riyadh): History, culture, and health care. Association of Black Nursing Faculty Journal, 16(4), 83-86.

Brown, R. T., Lambert, R., Devine, D., Baldwin, K., Casey, R., Doepke, K., ... Eckman, J. (2000). Risk-resistance adaptation model for caregivers and their children with sickle cell syndromes. Annals of Behavioral Medicine, 22(2), 158-169. https://doi.org/10.1007/BF02895780

Browning, N. A. (2013). "I am Bedu: the Changing Bedouin in a Changing World", Theses and Dissertations. 903. http://scholarworks.uark.edu/etd/903

Bull, M.J. (1990). Factors influencing family caregiver burden and health. Western Journal of Nursing Research, 12,758-776. 
Burnette, D., Duci, V., and Dhembo, E. ( 2017). Psychological distress, social support, and quality of life among cancer caregivers in Albania. PsychoOncology, 26: 779- 786. doi: 10.1002/pon.4081.

Canam, C. and Acorn, S. (1999). Quality of Life for Family Caregivers of People with Chronic Health Problems. Rehabilitation Nursing, 24: 192-200. doi:10.1002/j.2048-7940.1999.tb02176.x

Caplan, G. (1974). Support systems and community mental health. New York: Behavioral Publications

Caserta, M.S., Lund, D.A., Wright, S.D., \& Redburn, D.E. (1987). Caregivers to dementia patients: The utilization of community services. Gerontologist, 27: 209214

Cassel, J. C. (1976). The contribution of the social environment to host resistance. American Journal of Epidemiology, 104, 107-123.

Cobb, S. (1976). Social support as a moderator of life stress. Psychomatic Medicine, 38, 300-314.

Cohen, S., \& Wills, T. A. (1985). Stress, social support, and the buffering hypothesis. Psychological Bulletin, 98(2), 310-357.

Council of Health Services. (2020) Vision and tasks of the Council of Health Services in Saudi Arabia]. [website] (http://www.chs.gov.sa/ COHS/default.aspx, accessed 2 February 2020) [in Arabic] 
Country cooperation strategy for WHO and Saudi Arabia 2006-2011. (2007). Cairo, World Health Organization Regional Office for the Eastern Mediterranean, (EM/ARD/014/E/R).

Daly, B. P., Kral, M.C., \& Brown, R.T. (2008). Cognitive and academic problems associated with childhood cancers and sickle cell disease. School Psychology Quarterly, 23,12.doi: 10.1037/1045-3830.23.2.230

Dampier, C., Ely, E., Brodecki, D., \& O'Neal, P. (2002). Home management of pain in sickle cell disease: a daily diary study in children and adolescents. Journal of Pediatric Hematology and Oncology, 24, 643-647.

Da Silva, L. B. L., Ivo, M. L., de Souza, A. S., Pontes, E. R. J. C., Pinto, A. M. A. C., \& de Araujo, O. M. R. (2012). "The burden and quality of life of caregivers of sickle cell anemia patients taking hydroxyurea versus those not taking hydroxyurea". Revista Brasileira de Hematologia E Hemoterapia, 34(4), 270274. http://doi.org/10.5581/1516-8484.20120070

Davis, H., Schoendorf, K. C., Gergen, P. J., \& Moore, R. M., Jr. (1997). National trends in the mortality of children with sickle cell disease, 1968 through 1992. American Journal of Public Health, 87, 1317-1322.

Dean, A., \& Lin, N. (1977). The stress-buffering role of social support. Journal of Nervous and Mental Disease, ItiS, 403-417

Del-Pino-Casado, R., Frías-Osuna, A., Palomino-Moral, P. A., Ruzafa-Martínez, M., \& Ramos-Morcillo, A. J. (2018). Social support and subjective burden in caregivers 
of adults and older adults: A meta-analysis. PloS one, 13(1), e0189874.

https://doi.org/10.1371/journal.pone.0189874

Dich, N., Lange, T., Head, J., \& Rod, N. H. (2015). Work stress, caregiving, and allostatic load: prospective results from the Whitehall II cohort study. Psychosomatic medicine, 77(5), 539-547. doi:10.1097/PSY.0000000000000191

Edwards, C. L., Scales, M. T., Loughlin, C., Bennett, G. G., Harris-Peterson, S., De Castro, L.M., et al. (2005). "A brief review of the pathophysiology, associated pain, and psychosocial issues in sickle cell disease”. International Journal of Behavioral Medicine, 12, 171-179.

Edwards, R. \& Holland, J. (2013). What is qualitative interviewing?

Eiser, C. (1994). Effects of chronic illness on children and their families. Advances in Psychiatric Treatment, 3, 204-210.

Elamin, A. M. \& Omair, K. (2010). Males' attitudes towards working females in Saudi Arabia. Personnel Review, 39(6), 746-766.

El-Hazmi MA, Al-Swailem AR, Warsy AA, Al-Swailem AM, Sulaimani R, Al-Meshari AA. (1995). Consanguinity among the Saudi Arabian population. J Med Genet $1995 ; 32: 623-6$.

Ellison, C.G.; Levin, J.S. The Religion-Health Connection: Evidence, Theory, and Future Directions. Health Educ. Behav. 1998, 25, 700-720 
Evans, D., Hsu, J., \& Boerma, T. (2013). Universal health coverage and universal access. Bulletin of the World Health Organization. 91. 546-546A. 10.2471/BLT.13.125450.

Fletcher, M. (2000). The Quality of Australian Health Care: Current Issues and Future Directions, Commonwealth Department of Health and Aged Care 2000, Occasional Papers: Health Financing Series Volume 6

Frank RG, Thayer JF, Hagglund KJ, Vieth AZ, Schopp LH, Beck NC, et al. (1998). Trajectories

of adaptation in pediatric chronic illness: The importance of the individual. J Consult Clin Psychol 1998; 66:521-32.

Frank-Stromborg, M. (1988). Instrumentsfor clinical nursing research. Norwalk, CT: Appleton \& Lange.

George, L., \& Bearon, L. (1980). Qualityof life in older persons.New York: Human Sciences Press.

George, L.K. (1987). Easing caregiver burden: The role of informal and formal supports. In R.A. Ward \& S.S. Tobin (Eds.), Health in aging: Sociological issues and policy directions (133-158). New York: Springer.

George, K.K., \& Gwyther, L.P. (1986). Caregiver well-being: A multidimensional examination of family caregivers of demented adults. Gerontologist

Given, B., Stommel, M., Collins, C., King, S., \& Given, C.W. (1990). Responses of elderly spouse caregivers. Research in Nursing and Health, 13, 77-85. 
Glasdam S, Timm H, Vittrup R. (2010). Support efforts for caregivers of chronically ill persons. Clin Nurs Res 2010;19:233-65.;

Goldberg, Arnold \& Rickler, Kim. (2011). The role of family caregiver for people with chronic illness. Medicine and health, Rhode Island. 94. 41-2.

Goldberg S, Morris P, Simmons RJ, Fowler RS, Levison, H. (1990). Chronic illness in infancy and parenting stress: A comparison of three groups of parents. J Pediatr Psychol 1990; 15:347-58.

Goldblatt, H., Cohen, M., Azaiza, F., \& Manassa, R. (2013). Being within or being between? The cultural context of Arab women's experience of coping with breast cancer in Israel. Psycho-oncology, 22(4), 869-875. https://doi.org/10.1002/pon.3078

Golics, C., Basra, M., Salek, M., \& Finlay, A. (2013). The impact of patients' chronic disease on family quality of life: An experience from 26 specialties. International Journal of General Medicine, 6, 787-98

Gore, S. (1985). Social support and styles of coping with stress. In S. Cohen \& S. L. Syme (Eds.), Social support and health (pp. 263-280). New York: Academic Press.

Hamdan, S.S. (1990)., Social change in the Saudi family, Iowa State Universtiy Hamlett KW, Pellegrini DS, Katz KS. (1992). Childhood chronic illness as a family stressor. Journal of Pediatric Psychology 1992; 17:33-47 
Heller, K., Swindle, R. W., \& Dusenbury, L. (1986). Component social support processes: Comments and integration. Journal of Consulting and Clinical Psychology, 54(4), 466-470.

Henderson, D., \& Vandenberg, B. (1992). Factors influencing adjustment in the families of autistic children. Psychological reports, 71(1), 167-171. https://doi.org/10.2466/pr0.1992.71.1.167

Henderson, S., Byrne, D. G., Duncan-Jones, P., Scott, R., \& Adcock, S. (1980). Social relationships, adversity and neurosis: A study of associations in a general population sample. British Journal of Psychiatry, 136, 354-583.

House, J. S. (1981). Work stress and social support. Reading, MA: Addison-Wesley. Hoza, J., (2019). Is There Feminism in Saudi Arabia?. UF Journal of Undergraduate Research. 20. 10.32473/ufjur.v20i2.106192.

Ibrahim Saad Alsumaih, Fahad Abdulaziz Aldhuwayhi. (2015). Characteristics of Medical Services in the US Versus Saudi Arabia. Science Journal of Public Health. Vol. 3, No. 4, 2015, pp. 588-591. doi: 10.11648/j.sjph.20150304.29 Institute of Medicine (US) Committee on Palliative and End-of-Life Care for Children and Their Families; Field MJ, Behrman RE, editors. When Children Die: Improving Palliative and End-of-Life Care for Children and Their Families. Washington (DC): National Academies Press (US); 2003. CHAPTER 2, PATTERNS OF CHILDHOOD DEATH IN AMERICA. 
Jastaniah, W. (2011). Epidemiology of sickle cell disease in Saudi Arabia. Annals of Saudi Medicine, 31(3), 289-293. http://doi.org/10.4103/0256-4947.81540

Jensen, Mark P., Amanda E. Smith, Charles H. Bombardier, Kathryn M. Yorkston, Jordi Miro, and Ivan R. Molton. (2014). "Social Support, Depression, and Physical Disability: Age and Diagnostic Group Effects." Disability and Health Journal 2014:164-72.

Johansson, A., Anderzen-Carlsson, A., Ahlin, A. \& Andershed, B. (2012). Fathers' everyday experiences of having an adult child who suffers from long-term mental illness. Issues in Mental Health Nursing, 33(2), 109-117.

Juster R-P, McEwen BS, Lupien SJ. (2010). Allostatic load biomarkers of chronic stress and impact on health and cognition. Neurosci. Biobehav. Rev. 2010; 35(1):2-16. [PubMed: 19822172]

Kahn, R.L. \& Antonucci, Toni. (1980). Convoys Over the Life Course: Attachment Roles and Social Support. In P.B. Baltes \& O. Bream (Eds), Life span development and behavior., (vol. 3) (pp. 253-286). New York: Academic Press

Kaplan, B. H., Cassel, J. C., \& Gore, S. (1977). Social support and health. Medical Care, $15,47-58$.

Kari, Jameela. (2006). Chronic renal failure in children in the Western area of Saudi Arabia. Saudi journal of kidney diseases and transplantation: an official publication of the Saudi Center for Organ Transplantation, Saudi Arabia. 17. 1924. 
Katooa, N., Shahwan-Akl, L., Reece, J., \& Jones, L.M. (2015). Characteristics of Mothers with Chronically Ill Children in Jeddah, Saudi Arabia. International Journal of Nursing, 2, 59-73.

Kaufmann, G. M., \& Beehr, T. A. (1989). Occupational Stressors, Individual Strains, and Social Supports among Police Officers. Human Relations, 42(2), 185-197.

Ke, X., Liu, C. \& Li, N. (2010). Social support and Quality of Life: a cross-sectional study on survivors eight months after the 2008 Wenchuan earthquake. $B M C$ Public Health 10, 573 (2010) doi:10.1186/1471-2458-10-573

Keane, Brigid \& Defoe, Lindy. (2016). Supported or stigmatised? The impact of sickle cell disease on families. Community practitioner: the journal of the Community Practitioners' \& Health Visitors' Association. 89. 44-47.

Khalil, M., Al-Eidi, S., Al-Qaed, M., \& AlSanad, S. (2018). The future of integrative health and medicine in Saudi Arabia. Integrative medicine research, 7(4), 316321. doi:10.1016/j.imr.2018.06.004

Khaliq, A. (2012). The Saudi Healthcare System: A View from the Minaret. World health \& population. 13. 52-64. 10.12927/whp.2012.22875.

Lin, N., Woelfel, M.W., \& Light, S.C. (1985). Journal of Health and Social Behavior, Vol. 26, No. 3 (Sep. 1985), pp. 247-263

Long, D. E. (2003). The role of the extended family in Saudi Arabia. Retrieved from http://susris.com/2003/03/10/the-role-of-the-extended-family-in-saudi-arabia 
Mansour, A.A., Al-Osimy, M.H. (1993). A study of satisfaction among primary health care patients in Saudi Arabia. J Community Health. 1993; 18(3):163-73

Martin C. M. (2007). Chronic disease and illness care: adding principles of family medicine to address ongoing health system redesign. Canadian family physician Medecin de famille canadien, 53(12), 2086-2091.

McIntyre, L. L., \& Brown, M. (2018). Examining the utilisation and usefulness of social support for mothers with young children with autism spectrum disorder. Journal of intellectual \& developmental disability, 43(1), 93-101. doi: $10.3109 / 13668250.2016 .1262534$

McKinsey Global Institute Report (MGIR). (2015). Saudi Arabia beyond oil: the investment and productivity transformation: McKinsey global institute.

Memish, Z. A., Zumla, A. I., Al-Hakeem, R. F., Al-Rabeeah, A. A. \& Stephens, G. M. (2013). Family cluster of Middle East respiratory syndrome coronavirus infections. New England Journal of Medicine, 368(26), 2487-2494.

Metz, H., (1992). Saudi Arabia: A Country Study. Washington: GPO for the Library of Congress

Midence, K., Fuggle, P., \& Davies, S. C. (1993). "Psychosocial aspects of sickle cell disease

(SCD) in childhood and adolescence": a review. British Journal of Clinical Psychology, 32, ( Pt 3) (1993): 271-80. 
Midence, K., \& Shand, P. (1992). "Family and social issues in sickle cell disease". Health Visit, 65,441-443.

Miller, B., \& McFall, S. (1991). Stability and change in the informal task support network of frail older persons. Gerontologist, 31,735-745

Ministry of Health (MOH). (2009). Statistics book of the Ministry of Health, Kingdom of Saudi Arabia.

Ministry of Health. General Directorate of Statistics \& Information, Health statistic book. Riyadh (KSA): Ministry of Health; 2016.

Modell, B., \& Darlison, M. (2008). Global epidemiology of haemoglobin disorders and derived

service indicators. Bulletin of the World Health Organization, 86, 480-487.

doi: 10.2471/BLT.06.036673.

Mokdad AH, Jaber S, Abdel Aziz MI, et al. (2014). The state of health in the Arab world, 1990-2010: an analysis of the burden of diseases, injuries, and risk factors. The Lancet. Jan 20. DOI: 10.1016/S0140-6736(13)62189-3.

Montgomery, R.J.V., Gonyea, J.G., \& Hooyman, N.R. (1985). Caregiving and the experience of subjective and objective burden. Family Relations, 34, 19-26.

Moskowitz, J. T., Butensky, E., Harmatz, P., Vichinsky, E., Heyman, M. B., Acree, M., et al.

(2007). "Caregiving time in sickle cell disease: psychological effects in maternal caregivers”. Pediatric Blood Cancer, 48, 64-71. 
Mufti, M. (2004). Healthcare Development Strategies in the Kingdom of Saudi Arabia. Springer.

Naseem, S. \& Dhruva, K., (2018). Issues and challenges of Saudi female labor force participation and the role of vision 2030, International Journal of Economics and Financial Issues, 2017, 7(4), 23-27.

Ng, S. W., Zaghloul, S., Ali, H. I., Harrison, G. \& Popkin, B. M. (2011). The prevalence and trends of overweight, obesity and nutrition-related non-communicable diseases in the Arabian Gulf States. Obesity Reviews, 12(1), 1-13.

Obaid, N. (2015). "Saudi Arabia is emerging as the new Arab superpower." The Telegraph, May 5, 2015.

Ohene-Frempong, K., Weiner, S. J., Sleeper, L. A., Miller, S. T., Embury, S., Moohr, J. W., et al.

(1998). Cerebrovascular accidents in sickle cell disease: rates and risk factors. Blood, 91,288-294.

Padilla, G. V., Grant, M. M., \& Ferrell, B. (1992). Nursing research into quality of life. Quality of life research: an international journal of quality of life aspects of treatment, care and rehabilitation, 1(5), 341-348. https://doi.org/10.1007/BF00434948

Pietruschka, U. (2006). "Bedouin". In McAuliffe, Jane Dammen (ed.). Encyclopaedia of the Qur'ān. Brill. doi:10.1163/1875-3922_q3_EQSIM_00046 
Platt, O.S., Brambilla, D.J., Rosse, W. F., Milner, Paul F., Castro, O., Steinberg, M.H., Klug, P. P., (1994). Mortality In Sickle Cell Disease -- Life Expectancy and Risk Factors for Early Death. New England Journal of Medicine. 1639-1644. Vol. 330, No. 23

https://www.nejm.org/doi/full/10.1056/NEJM199406093302303

Post M. W. (2014). Definitions of quality of life: what has happened and how to move on. Topics in spinal cord injury rehabilitation, 20(3), 167-180. doi:10.1310/sci2003-167

Pratt, C.C., Schmall, V.L., Wright, S., \& Cleland, M. (1985). Burden and coping strategies of caregivers to Alzheimer's patients. Family Relations, 34.27-33.

Raina, Parminder \& O'Donnell, Maureen \& Rosenbaum, Peter \& Brehaut, Jamie \& D Walter, Stephen \& Russell, Dianne \& Swinton, Marilyn \& Zhu, Bin \& Wood, Ellen. (2005). The Health and Well-Being of Caregivers of Children with Cerebral Palsy. Pediatrics. 115. e626-36. 10.1542/peds.2004-1689.

Reblin, M., \& Uchino, B. N. (2008). Social and emotional support and its implication for health. Current opinion in psychiatry, 21(2), 201-205.

doi:10.1097/YCO.0b013e3282f3ad89

Rincon, S. (2019). Divorce in the Arab Gulf: A Sign of the Changing Times, Inside Arabia

Riyadh Population. (2020-02-17). Retrieved 03/01/2020, from worldpopulationreview.com/world-cities/riyadh/ 
Robinson, K.M. (1990). Predictors of burden among wife caregivers. Scholarly Inquiry for Nursing Practice: An International Journal, 4, 189-203.

Saudi Arabia Ministry of Justice, https://www.stats.gov.sa/sites/default/files/marriage_and_divorce_statistics_2019 en.pdf

Saudi Arabia High Commission for the Development of Riyadh, 2004 Population Survey, http://www.arriyadh.com/ar/AboutArriy/Left/Statistics/getdocument.aspx?f=/ope nshare/ ar/AboutArriy/Left/Statistics/Statistics3.doc_cvt.htm.

Saudi Arabian Ministry of Health. (2005). Health statistic book for the year of 2005. Retrieved January 2020 from http://www.moh.gov.sa/stattistics/1425/index.html Sawyer EH. Family functioning when children have cystic fibrosis. J Pediatr Nurs $1992 ; 7: 30411$

Scott, J.P., Roberto, K.A., \& Hutton, J.T. (1986). Families of Alzheimer's victims: Family support to the caregivers. Journal of the American Geriatric Society, 34,348-354.

Shiba, Koichiro \& Kondo, Naoki \& Kondo, Katsunori. (2016). Informal and Formal Social Support and Caregiver Burden: The AGES Caregiver Survey. Journal of Epidemiology. 26. 10.2188/jea.JE20150263.

Shinn, M., Lehmann, S. and Wong, N. W. (1984), Social Interaction and Social Support. Journal of Social Issues, 40: 55-76. doi:10.1111/j.1540-4560.1984.tb01107.x 
Song, L., Son J., \& Lin, N. (2011). “Social Support.” Pp. 116-128 in The Sage Handbook of Social Network Analysis, edited by John Scott and Peter J. Carrington. London: SAGE.

Spitzer, W.O., (1986). State of science 1986: quality of life and functional status as target variables for research. Journal of chronic diseases, 1987, Vol: 40, Issue: 6, Page: $465-71$

Standen PJ, Hinde FRJ, Lee PJ. (1985) Family involvement and metabolic control of childhood

diabetes. Diabet Med 1985; 2:137-40.

Strom, J. L., \& Egede, L. E. (2012). The impact of social support on outcomes in adult patients with type 2 diabetes: a systematic review. Current diabetes reports, 12(6), 769-781. doi:10.1007/s11892-012-0317-0

Sullivan, K. (2012). In Saudi Arabia, unemployment and booming population drive growing poverty. The Washington Post.

Thoits, P. A. (1985). Social support processes and psychological well-being: Theoretical possibilities. In I. G. Sarason \& B. Sarason (Eds.), Social support: Theory, research and applications (pp. 51-72). The Hague, The Netherlands: Martinus Nijhof.

Thoits, Peggy A. (2011). "Mechanisms Linking Social Ties and Support to Physical and Mental Health." Journal of Health and Social Behavior 52(2):145-61. 
Todd RH, Hinton DW, Burch G., Ludwig, AK and Ruff, J., "Saudi Arabia Sociological Research Project" (1977). Publications Archives, 1963-2000. 10.Umberson, D., \& Montez, J. K. (2010). Social Relationships and Health: A Flashpoint for Health Policy. Journal of Health and Social Behavior, 51(Suppl), S54-S66. http://doi.org/10.1177/0022146510383501

Trivette CM, \& Dunst CJ (1992). Characteristics and influences of role division and social support among mothers of preschool children with disabilities. Topics in Early Childhood Special Education, 12, 367-385. doi:10.1177/027112149201200308

Turner, R.). (1983). Direct, indirect and moderating effects of social support upon psychological distress and associated conditions. In H. B. Kaplan (Ed.), Psychosocial stress: Trends in theory and research (pp. 105-155). New York: Academic Press.

Umberson, Debra, and Jennifer Karas Montez. (2010). "Social Relationships and Health a Flashpoint for Health Policy." Journal of Health and Social Behavior 51(1 suppl):S54-S66.

United Nations Population Division. World Urbanization Prospects: 2018 Revision Varshney, D. (2019). The Strides of the Saudi Female Workforce: Overcoming Constraints and Contradictions in Transition. 
[Vision and tasks of the Council of Health Services in Saudi Arabia]. Council of Health Services [website] (http://www.chs.gov.sa/ COHS/default.aspx, accessed 2 February 2020) [in Arabic]

Vrabec, N. J. (1997), Literature Review of Social Support and Caregiver Burden, 1980 to 1995. Image: The Journal of Nursing Scholarship, 29: 383-388. doi:10.1111/j.1547-5069.1997.tb01062.x

Walston, S., Al-Harbi, Y., \& Al-Omar, B. (2008). The changing face of healthcare in Saudi Arabia. Annals of Saudi medicine, 28(4), 243-250. doi:10.5144/02564947.2008.243

Weiss MJ (2002). Hardiness and social support as predictors of stress in mothers of typical children, children with autism, and children with mental retardation. Autism, 6, 115-130. doi: 10.1177/1362361302006001009 [PubMed: 11918107]

Wilcox, B. L. (1981). Social support, life stress, and psychological adjustment: A test of the buffering hypothesis. American Journal of Community Psychology, 9, 371386.

World Health Organization. (2011). World Health Constitution. Switzerland. Retrieved from http://www.who.int/governance/eb/constitution/en/ World Health Organization (WHO). (2010). World health statistics 2010. Retrieved from http://www.who.int/topics/chronic_diseases/en/World Health Zarit, S.H., Reever, K.E., \& Bach-Peterson, J. (1980). Relatives of the impaired elderly: Correlates of feelings of burden. Gerontologist, 20,649-655. 
APPENDIX A

\section{Caregiving and Social Support among Women in the Kingdom of Saudi Arabia}

This survey will help understand the experience of caretaking and social support among people like you. If you have any questions or want to know more about the study, please contact albugaminouf@gmail.com.

Section 1 General experience as a caregiver and your perceived overall health

1. Do you live with the patient that you care for?

Yes

No

2. What is your relationship to the patient?

Parent

Sibling

Child

Spouse

Grandparent

Other, please specify 
Thinking about the last 12 months,

\begin{tabular}{|c|c|c|c|c|c|}
\hline & 0 & 1 & 2 & 3 & $4+$ \\
\hline $\begin{array}{l}\text { 3. About how often have you accompanied the } \\
\text { patient to their regular appointments at the } \\
\text { hospital? }\end{array}$ & & & & & \\
\hline $\begin{array}{l}\text { 4. About how many times have you } \\
\text { accompanied the patient to the hospital for an } \\
\text { emergency visit? }\end{array}$ & & & & & \\
\hline $\begin{array}{l}\text { 5. About how many times was the patient } \\
\text { actually admitted to the hospital? }\end{array}$ & & & & & \\
\hline
\end{tabular}

6. Caregiving is defined as providing care to a family member to help with activities of daily

living (ADLs). ADLs include grooming/personal hygiene, dressing, eating, transferring,

toilet/continence. On an average day, about how much time do you spend helping the patient with at least one ADL?

Less than 4 hours

4 hours

4-8 hours

8-16 hours

More than 16 hours 
7. In general, would you say your health is: (SF-36)

$\begin{array}{ll} & \text { Excellent } \\ & \text { Very good } \\ & \text { Good } \\ & \text { Fair } \\ & \text { Poor }\end{array}$

8. Compared to one year ago, how would you rate your health in general now? (SF-36)

Much better

Somewhat better

About the same

Somewhat worse

Much worse 
Question 9-17 will ask you about whether or not you have been told by a doctor or other health professional that you have any of the following conditions. (HCS)

\begin{tabular}{|l|l|l|l|}
\hline & Yes within the last year & Yes more than a year & No \\
\hline 9. Diabetes or sugar diabetes & & & \\
\hline 10. High blood pressure & & & \\
\hline 11. Heart disease & & & \\
\hline 12. High cholesterol & & & \\
\hline $\begin{array}{l}\text { 13. Chronic Obstructive } \\
\text { Pulmonary Disease (COPD) or } \\
\text { emphysema }\end{array}$ & & & \\
\hline 14. Cancer & & & \\
\hline 15. Depression & & & \\
\hline 16. Anxiety & & & \\
\hline 17. Another ongoing health \\
condition (tell us):
\end{tabular}




\section{Section 2 Caregiver background information}

Questions 22-32 will ask you about some of your background information as a caregiver. (HCS)

22. Are you male or female?

Male

Female

23. What year were you born?

24. What is your marital status?

Single, never married

Married

Widowed

Divorced

Other (Please specify

25. What is the highest level of education you have completed?

Less than high school

High school diploma

Vocational training or 2-year degree

4-year university degree or more 
26. Are you currently employed?

Yes, employed by someone else (Please specify your occupation

Yes, self-employed

Not currently employed

Retired

Other (Please specify

27. What kind of area do you live in?

Urban

Rural

28. What was your gross household income for last year (2017)?

29. How many people live in your household?

30. How many people living in your household work?

31. How much does transportation of the patient to the hospital cost per year?

32. Can your family afford the treatment and medications?

Yes

No 


\section{APPENDIX B}

\section{INTERVIEW GUIDE Opening question}

- Can you tell me about your feelings when you first learn about your family member's condition? How did you cope with those feelings?

\section{Main interview questions (overview)}

1. Are you comfortable talking about your feelings in front of other people? Who do you usually talk to about those feelings?

2. Do you talk about your family member's condition in front of other people?

3. How supportive are your family and relatives regarding you providing care to your sick family member? Do they live close by for when you need their help? Do you ask for their advice when you need it? To what extent are you satisfied about the support they provide? (Husband, Children, Parents, Siblings, Friends, Relatives, etc.)

4. If you have an important appointment to go to, do you have someone who can help you take care of your sick family member? If yes, do you mind telling me who that person is?

5. What is your outlook on your future besides providing care to your family member? What is your outlook on your sick family member's future?

6. Do you go to places where there are other people with family members suffering from chronic diseases? If yes, where and how often do you usually meet with them? Have you benefited from going to these meetings? If yes, in what ways did you benefit from attending these meetings?

7. Do you use any support services e.g. websites/counseling to help you with your feelings? If so, what do you use and?

8. How does your family member's condition affect your social life? (visiting relatives, making friend, etc.)

9. Can you think of any activities/hobbies that you used to do which you can't now as a result of your relative's condition?

10. Do you do any physical activities with your sick family member now? Or does your sick family member do any physical activities with other family members?

11. Does your relative's condition have any effect on your housework? If so, how?

12. Has your family member's condition affected your relationship with your other family members? If so, how? 
13. Are you able to meet the needs of your other family members now that you have to take care of your sick family member?

14. How would you describe the communication within your family members?

15. Has taking care of your sick family member affected your relationship with your spouse?

16. Has your role as a primary caregiver of your sick family member affected your ability to maintain a healthy relationship (solving problems) with your other family members such as your husband?

17. Can you tell me who is the medical proxy for your sick family member's healthcare?

18. Could you please describe an instance where you're being the primary caregiver but not the medical proxy affected your ability to make a medical decision for your sick child?

19. Do you buy anything special of different as a result of your relative's condition? Can you explain what and why?

20. Do you have any financial problems associated with your family member's condition? What is the cause of these?

21. Does your family member's condition affect your job at all? If so, how?

22. Has your sick family member's condition affected your ability to enjoy life such as going on vacation? If so, how?

23. Does your family member's condition affect your sleep? If so, why?

24. Has your family member's condition affected your health at all? If so, how?

25. Have you changed what you eat at all? If so, how? Did your appetite from what it was in the past? How?

\section{- Closure}

26. Is there anything else you can think of that you haven't told me?

27. Is there anything else you would like to discuss?

28. Thank them for their time. 
APPENDIX C

\section{PARTIAL INTERVIEW GUIDE WITH A SAMPLE OF PARTICIPANTS' ANSWERS}

\section{Can you tell me about your feelings when you first learn about your family member's condition? How did you cope with those feelings?}

Participant 1 - It was a big shock. I collapsed and then I started crying. Every time I try to get on with life, I remember my daughter's disease and then I start crying once again. I dealt with the situation by writing and reading some useful books such as Because you are GOD. I also follow optimistic people in the app Snapchat.

Participant 4 - This is God's will and we need to accept what He planned for us

Participant 5 - I was heartbroken and devastated. I was thinking about my other children. I was crying. I overcame this feeling by depending on God.

Participant 7 - I accepted what God planned for us

Participant 11 - I was shocked, but I had had children before with the same condition. Nevertheless, I was still shocked. But now, I'm accepting the situation, and this is something I can't avoid.

\section{Are you comfortable talking about your feelings in front of other people?}

Participant 10 - No, because people around me don't know about my suffering. Only my family does. But even when I express my feelings to them, they don't fully understand what I'm going through.

Participant 11 - No because I don't want my children to feel like they're sick. One of them is eight, so I tell him that he's fine and I try to be positive towards him. But if my children aren't with me, and my sisters are with me, then I can talk with them about it. But never with others.

\section{Who do you usually talk to about those feelings?}

Participant 4 - No one. I just pray to God.

Participant 14 - My friend here in the hospital talks to me. And my sister does too. Women here in the hospital try to support each other. 


\section{What is your outlook on your future besides providing care to your family member? What is your outlook on your sick family member's future?}

Participant 18 - I hope God will make me patient. I'm optimistic and, God willing, if my daughter passes away, I will maintain my patience because it's Gods will. But I still don't know about my daughter's future or mine.

Participant 26 - I do not have a future.

Participant 30 - There is no future for me; God is the only one who could help him.

Do you use any support services e.g. websites/counseling to help you with your feelings? If so, what do you use and?

Participant 1 - One of the social media sites I use is Snapchat. No, I do not like searching up stuff regarding my daughter's disease because I usually can't find any helpful stuff. So, it increases my depression even more.

Participant 3 - I search on Google about my daughter's situation and I read about it.

Participant 6 - Snapchat and Instagram

Participant 9 - No, except on the Internet and then just for topics related to my son's disease.

Participant 12 - No, but I use Twitter sometimes. When I accompany my daughter to the hospital, I try to get some people's numbers and meet up with them if I can to talk about how their children are doing.

Participant 13 - Instagram or Twitter

Participant 18 - I just read online, but I'm not involved in any social media groups.

Participant 19 - I didn't go anywhere, but there is a WhatsApp group that I joined with parents that have kids with the same illness as my children. I found the WhatsApp group from my child's doctor. What I got from this group was I found a woman that has a child with the same medical condition as mine. I learned from her that after exactly 7years her child didn't need to take the medicine anymore. So, I use her methods to help. I read about the illness on Google and Twitter. At first, I was just reading randomly about the medicine to treat the disease, but it wasn't a very good idea for me to read it online because it showed me the bad side of the disease. 
Participant 24 - No. Nothing

How does your family member's condition affect your social life? (visiting relatives, making friend, etc.)

Participant 1 - Yes, it has affected my social life quite a bit. For example two days ago, there was a big party. I could not go because there is no one that can replace me in taking care of my daughter, however.

Participant 27- It affects me a lot financially, psychologically, and mentally.

Can you think of any activities/hobbies that you used to do which you can't now as a result of your relative's condition?

Participant 3 - Visiting, hanging out and enjoying my time.

Participant 4 - I used to write stories but now I don't have time due to a lot of responsibility.

Participant 6 - I used to go to the gym but now I don't. I am mentally exhausted.

Participant 12 - After 4 years, our lives have changed since we now always go to the hospital for our daughter's appointments. Before we used to travel and go out. There were no obstacles and lines we could cross.

Do you do any physical activities with your sick family member now? Or does your sick family member do any physical activities with other family members?

Participant 11 - No, but we all go out to parks. But if I'm tired, my young daughter goes to the park with her siblings.

Participant 21- Yes, a lot of activities such as swimming, soccer, games

Participant 27 - Hand crafting.

Does your relative's condition have any effect on your housework? If so, how?

Participant 4 - Yes, I barely could make lunch for my kids, my sleeping became very spotty and unrefreshing, and the house duties became hard. 
Participant 5 - The housework is on my mind, but i still need to teach my kids and take care of them. But sometimes, if I am really exhausted, I couldn't take care of them or barely do any of the housework.

Participant 10 - Yes, I delay some of the housework until he sleeps. Sometimes I get help from my sister-in-law, but she is not always there. My husband takes them out some time so I can finish some housework.

\section{Has your family member's condition affected your relationship with your other family members? If so, how?}

Participant 18 - No. There is no time for arguing because everyone is doing their work and attending to other priorities.

Participant 22 - Sometimes there's little jealousy from other family members because we care about my sick patient more.

\section{How would you describe the communication within your family members?}

Participant 5 - It's been positive. They feel empathy towards my sick daughter. My relationship with my kids is good since I am caring about them. And I try to do something special for her. My relationship with my husband is bad because I want to travel to Jordan because I have heard that there is a good doctor. But my husband didn't give me a permission to go and take my daughter for the treatment. He said that I could go, but that I would need to leave our daughter at home. So this is not good. Because I'm going with my parents to see this same doctor, and they wanted to take my daughter as well, my husband still wouldn't allow me to do that. I'm going to be divorcing him.

Participant 23 - Yes, it affects a lot because there are a lot of appointments and I have to leave my house sometimes, and sometimes I have to sleep in a hospital with her. The relationship is better and it's become stronger. The family members became more caring for her mentally and physically. My relationship with my extended family is affected because of the appointments. I rarely ever come to family gatherings any more.

\section{Can you tell me who is the medical proxy for your sick family member's healthcare?}

Participant 3 - Me or my husband, if he is around. Yes, they did an endoscopy procedure with my permission.

Participant 5 - The mother. Yes, but I still need to tell him in order to avoid a confrontation with him and his evil temper. 
Participant 6 - Both my husband and I make the decisions. I can't make decisions without him knowing about it

Participant 8 - I asked her father. And then I sign the important paper. I cannot do it alone. I need to ask for advice from my husband, and the doctor.

Participant 9 - His dad. I need to call him

Participant 10 - The father. I didn't have enough knowledge. My husband is more educated in this matter and his decisions are better than mine.

Participant 12 - Me. For example, when the doctor said my daughter needed to be in the hospital her father said that there's no need to. But I declined to agree with my husband and let my daughter stay to get her treatment.

Participant 13 - Me and my husband.

Participant 14 - For a big decision like surgery we should notify her dad to get his consent. For example, my daughter needs surgery for an ulcer in her stomach, but my husband didn't agree with this idea because his mother wasn't convinced then we didn't need to do it.

Participant 17 - At the beginning it was hard because the father's signature is required for any thing to happen, whether it's for surgery, x rays, and more. But now I have obtained the Family Card, and this lets me do the signing without needing the father's consent.

Participant 21- Me and my husband. Yes, if there is an emergency that need an urgent decision and act.

Participant 23 - Her father. Yes. Like deciding to take biopsy and the doctor took it after I agreed. Then adenoid and tonsils surgery because it's for the best for my daughter's health. In the future maybe she might need to get a kidney transplant and I don't mind.

Participant 26 - The mother. I need to go back to his dad and get his opinion on everything, either big or small, including the doctor appointments.

\section{Does your family member's condition affect your job at all? If so, how?}

Participant 5 - Kind of because I'm going to work exhausted because I'm staying up overnight caring for my daughter and then bring her to my sister house. So, when I show up for work, my boss is getting work from an exhausted body. 
Participant 22 - Yes, I left my school this year.

Participant 29 - Yes, I wasn't able to complete my schooling.

\section{Does your family member's condition affect your sleep? If so, why?}

Participant 6 - It affected my sleeping schedule a lot. I barely sleep 3 hours in a day. So I sleep one day and the other day I do not. I am exhausted like any other mother.

Participant 8 - Of course! I feel like I'm losing my mind. If my daughter sleeps at night, then I take advantage of the time by praying. But in the morning when I am trying to sleep, the nurses and doctors are always coming in and out of the room

Participant 9 - I barley sleep. I only sleep accidently when I'm tired.

Participant 28 - Yes, a lot. For example, during the (SCD) crises sometimes it reached the point where I would go 3 days without sleeping.

\section{Has your family member's condition affected your health at all? If so, how?}

Participant 5 - Yes. Emotionally, a lot. I sometimes wake up a night crying. My sisters, who are helping me, are doing their best, but you know everyone's busy with their own lives.

Participant 11 - Yes, mentally but nothing like diabetes, and high blood pressure. But emotionally and mentally I feel ill.

Participant 15 - Yes, he's heavy and I need to carry him, so my muscles are affected and my back

also. It affects me emotionally and I feel intense pressure all over.

Participant 26 - Yes. It caused me clogged arteries, blood pressure, and diabetes. I wish I could find someone who can help

\section{Have you changed what you eat at all? If so, how? Did your appetite from what it was in the past? How?}

Participant 9 - Yes, my appetite is worse.

Participant 18 - My appetite towards food depends on my kid's situation. 
Appendix D

IRB approval

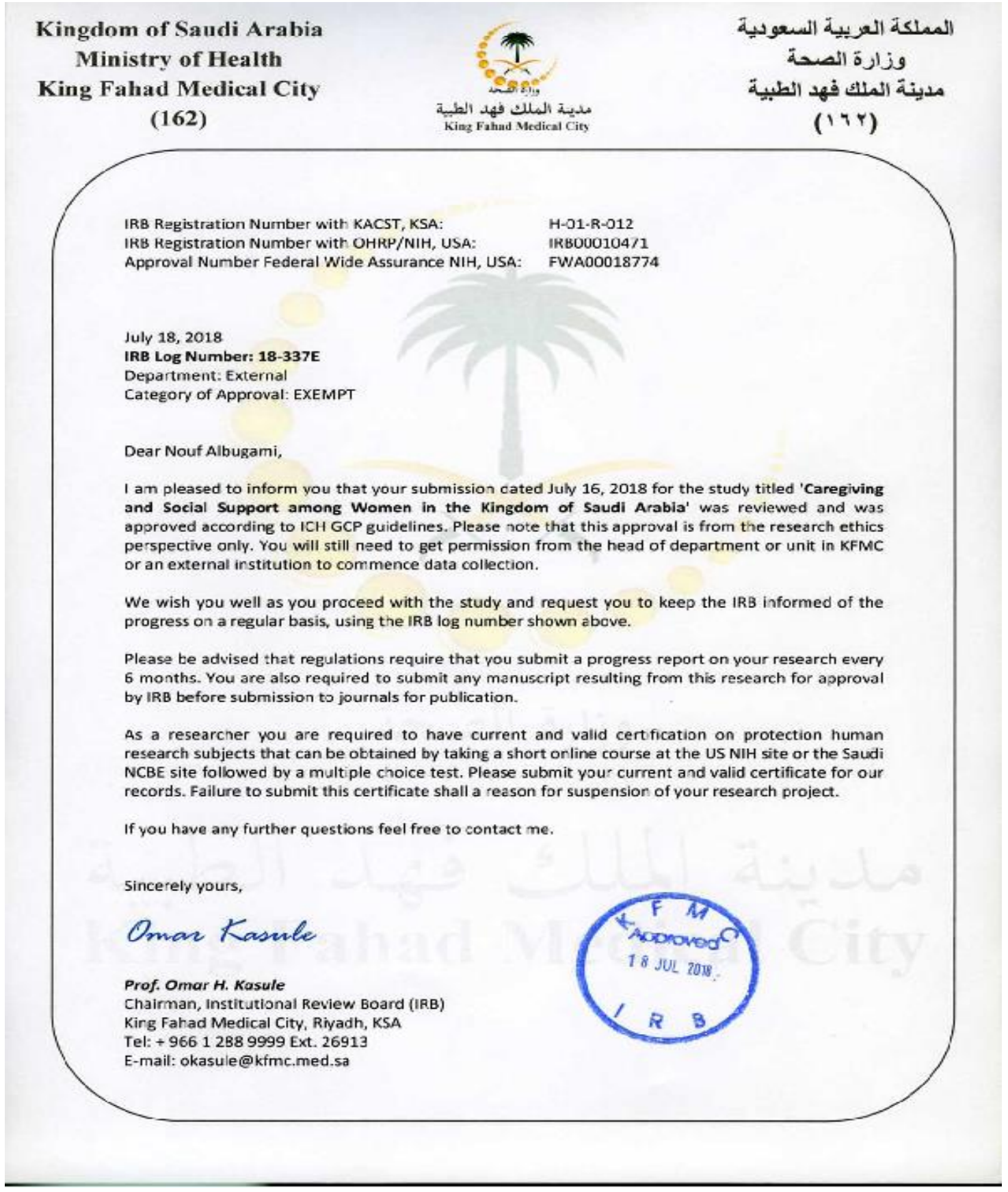


Appendix E

\section{Approval by the head of children specialized hospital}

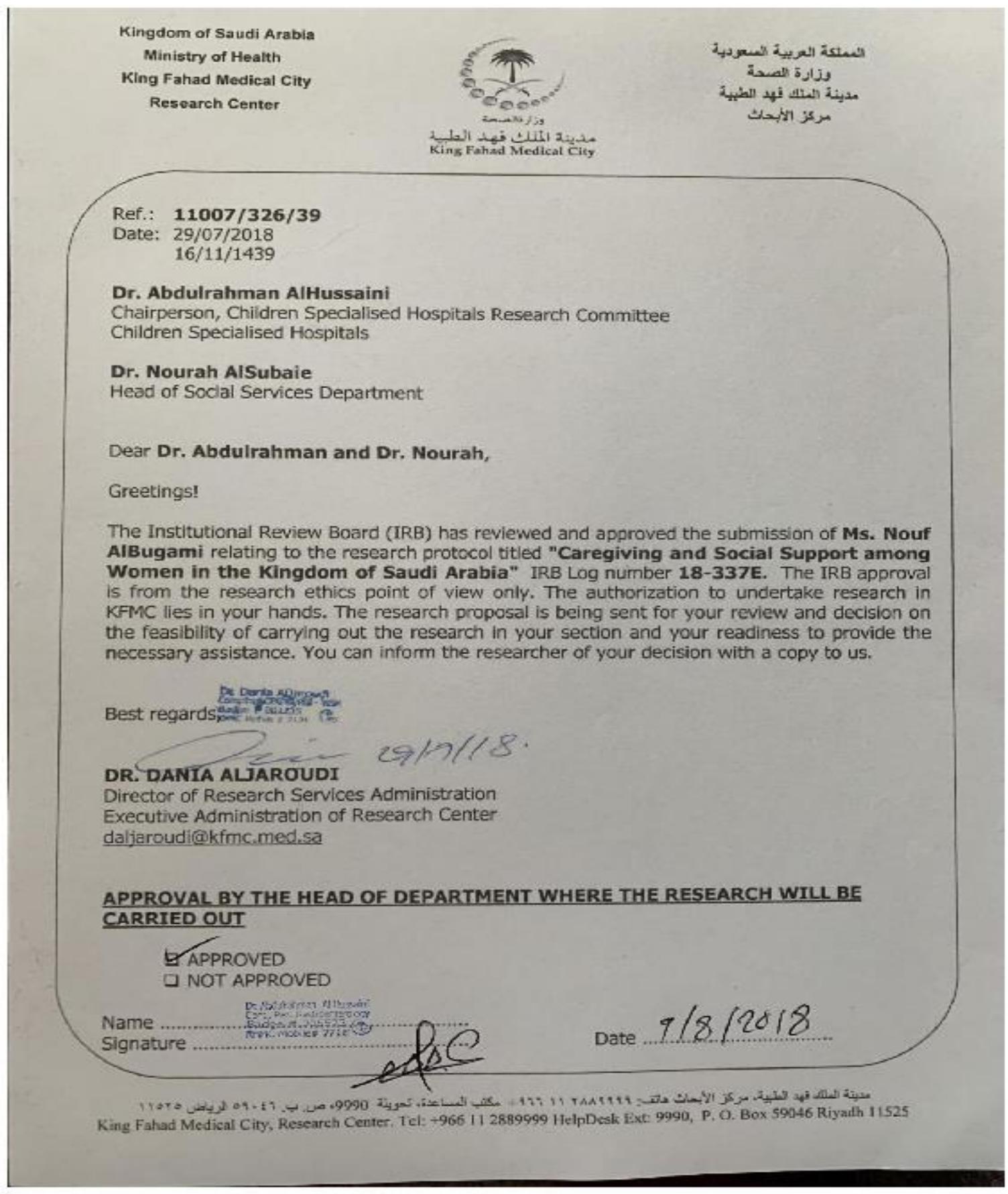

